\title{
CHAPTER ELEVEN
}

\section{THE THEORY OF SENSATION, THOUGHT AND \\ THE SOUL IN THE HIPPOCRATIC TREATISE REGIMEN: ITS CONNECTIONS WITH EMPEDOCLES AND PLATO'S TIMAEUS}

\begin{abstract}
Among the sixty or so medical treatises preserved under the name of Hippocrates, the treatise Regimen, despite its title, is not entirely dedicated to what ancient doctors meant by regimen. Whilst in book 2 (chs. 37-66) we find the most developed and systematic catalogue in the Hippocratic Corpus on the natural and artificial properties of the various ingredients of regimen (which, according to the ancients, comprised not only food and drink, but also exercise), the work's content is much richer and more diverse. The author of Regimen dedicates his entire first book (chs. $1-36)$ to a discussion of anthropology, because he is convinced that it is not possible to study regimen correctly without prior, and profound knowledge of the nature of man in his environment. Thus, the treatise belongs to a group of 'philosophical' Hippocratic works, i.e. treatises that establish a connection between the nature of man and the nature of the universe, between anthropology and cosmology. We find in Regimen, as Robert Joly, its most recent editor and commentator highlighted, the "clearest and most accurate formula articulating the doctrine of macrocosmos-microcosmos":

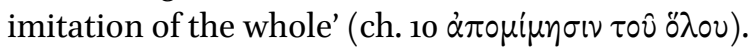

It is essentially for this cosmological anthropology and for its connections with pre-Socratic philosophy that the treatise has attracted scholarly attention from the end of the nineteenth century onwards. Rather than giving a detailed account of the history of scholarship on this work, I would like to highlight the more important stages of this interpretative history and to situate the present study in this history because, to an extent, it was part of it. The first important monograph on Regimen was published in 1899 by C. Fredrich in his Hippokratische Untersuchungen; 2 the second was by a

${ }^{1}$ R. Joly (with S. Byl), Hippocrate. Du régime, in Corpus medicorum graecorum (CMG), I, 2, 4, (Berlin, 1984), p. 241 (2nd ed. revised and corrected by S. Byl, 2003).

2 C. Fredrich, Hippokratische Untersuchungen, (Philologische Untersuchungen 15) (Berlin, 1899), pp. 81-230.

This is an open access chapter distributed under the terms of the CC-BY-NC License. 
Belgian philosopher, Robert Joly, who published, more than half a century later in 196o, his Recherches sur le traité pseudo-hippocratique Du Régime. ${ }^{3}$ Between these two dates, Hippocratic studies made great progress, above all in Germany (with the works of Ilberg, Wellmann, Diels, Pohlenz, Deichgräber, Edelstein and Diller), in Britain (with Jones' Loeb edition), but also in France, notably under the impetus of philosophers who, in the first half of the century, were ahead of the philologists. Since I have the honour of speaking in front of an audience of philosophers, I will briefly recount their role in the development of Hippocratic studies by recalling the principal names. Monseigneur Diès, at the start of the century, highlighted in his studies in the Revue critique d'Histoire de la Philosophie antique, collected together in 1926 under the title Autour de Platon. Essai de critique et d'histoire, not only the scientific interest of the Hippocratic Corpus, but also its importance for the history of Greek philosophy: "all, or nearly all, of the questions it asks are echoed in the history of Greek philosophy, and particularly in that of the great Socratic schools" ${ }^{\text {- }}$ I hope that my paper will be a fitting illustration of this attractive proposition. At the time of intense academic study of the history of ancient medicine, particularly thanks to German and English scholarship, Diès hoped that French scholarship would reclaim the very important place that it had held in the nineteenth century with Littré, Daremberg and Pétrequin. This renaissance came from the Ancient Philosophy Department of the Sorbonne, under the direction of Léon Robin, and then Emile Bréhier. Pierre-Maxime Schuhl, a student of Léon Robin, wrote a chapter on ancient and modern medicine in his doctoral thesis entitled La formation de la pensée grecque, published in $19344^{5}$ Another member of this research group, Paul Kucharski, also took an interest in the Hippocratic Corpus, in particular because of the famous passage of Plato's Phaedrus on the Hippocratic method, in an article that appeared in the Revue des Études grecques in $1939 .{ }^{6}$ A new sign of the renaissance of Hippocratic studies amongst specialists in ancient philosophy was the

${ }^{3}$ R. Joly, Recherches sur le traité pseudo-hippocratique Du Régime, (Bibliothèque de la Faculté de Philosophie et Lettres de l'Université de Liège, 156) (Paris, 1960).

4 A. Diès, Autour de Platon. Essai de critique et d'histoire. 2nd ed. revised and corrected, (Collection d'études anciennes) (Paris, 1972), p. 15.

${ }^{5}$ P.M.-Schuhl, La formation de la pensée grecque. Introduction historique à une étude de la philosophie platonicienne, (Bibliothèque de philosophie contemporaine) (Paris, 1934) (2nd ed. 1949).

${ }^{6}$ P. Kucharski, "La méthode d'Hippocrate dans le Phèdre," Revue des Études grecques 52, (1939), 301-357. 
attractive translation and rich commentary of Ancient Medicine by A.J. Festugière, published in 1948. ${ }^{7}$ However, it was Louis Bourgey, who was introduced to the Greek doctors of the Hippocratic corpus by Léon Robin, who earned the merit of crowning this renaissance of Hippocratic studies coming from French philosophy. Indeed, he is the only philosopher to have dedicated his entire doctoral thesis to the Hippocratic Corpus, published in 1953 under the title "Observation et expérience chez les médecins de la Collection hippocratique." This takes us up to the middle of the century. Continuing this sketch of Hippocratic studies in France, we now turn to the philologists, in particular from the Department of Greek at the Sorbonne, who took things further in the second half of the century. Fernand Robert founded the Hippocratic seminar at the Sorbonne and trained numerous students, who in turn had their own students; Jean Irigoin also played a decisive role in the study of the Hippocratic textual tradition through his courses at the École Pratique des Hautes Études, and later at the Collège de France. The story becomes more complicated here because of the very fruitful collaboration between philologists and historians of medicine, in particular Mirko Grmek, and then the internationalisation of Hippocratic research following the establishment of the Hippocratic colloquia, which took place every three years after the first colloquium held at Strasburg in 1972, which was organised by a professor of philosophy, Louis Bourgey, and myself, when I was professor of philology at Strasburg. I draw attention to this first colloquium, whose proceedings were published in $1975,{ }^{9}$ simply to highlight that it constitutes the coming together of two French traditions that developed independently of each other, and at different times: the philosophical tradition with Léon Robin, of whom Louis Bourgey was a student, and the philological tradition with Fernand Robert, of whom I was a student.

We return to the sixties, when Joly published his monograph on Regimen. Despite the renaissance of Hippocratic studies in the first half of the twentieth century, Joly notes in the introduction to his study that Regimen had not benefited from this to the same extent as other treatises. In fact, the only monograph on the treatise between that of Fredrich and that of Joly is a

\footnotetext{
${ }^{7}$ Hippocrate. L'Ancienne Médecine. Introduction, traduction et commentarire, (Études et Commentaires 4) (Paris, 1948).

${ }^{8}$ L. Bourgey, Observation et expérience chez les médecins de la Collection hippocratique (Paris, 1953).

${ }^{9}$ L. Bourgey and J. Jouanna (eds.) La Collection hippocratique et son rôle dans l'histoire de la médecine, (Leiden, 1975).
} 
German dissertation from Tübingen in 1933 by Adolf Palm..$^{10}$ Robert Joly had the merit of not only devoting to Regimen a rich and well-informed monograph of 260 pages, but also of publishing two editions of the treatise, one in 1967, published in the Collection des Universités de France $(C U F),{ }_{11}^{11}$ and the other in 1984, which we might call an editio maior, comprising not only the critical text and translation as in 1967 , but also a commentary that is both abundant and sober. This second edition, prepared in collaboration with his student Simon Byl, was published in the collection Corpus medicorum graecorum $(C M G)$, and so had an international readership. ${ }^{12}$ It incorporates the results of research on Regimen prior to the 1980 .

Since my own work has focused on other Hippocratic treatises, in particular the treatise Nature of Man, which was the subject of my doctoral thesis and published in the $C M G$ in 1975 , let me explain how I first became interested in the treatise Regimen by reading out something that is usually ignored, i.e. page VIII of Robert Joly's edition of Regimen, published in the CUF in 1967: "In accordance with the statutes of the Association Guillaume Budé, this volume was submitted for approval to the technical committee, which assigned to Jacques Jouanna the task of revision and of overseeing its correction in collaboration with Robert Joly." This administrative formula allows us to relive a bit of history: my teacher Fernand Robert, who originally promoted the edition of Hippocrates in the Collection des Universités de France had entrusted to me, when I was a young lecturer in Greek at the University Paris-Nanterre, the important task of revising Robert Joly's edition, which inaugurated the edition of this work of Hippocrates. The task of revision consists not only, as some people may think, in correcting factual errors; it is a revision concerned just as much with the establishment of the text as with the translation. This revision led to my interest in the theory of perception and intelligence in Regimen. In 1966, a year before the publication of the edition of Regimen in the $C U F$, I presented a paper to the Société pour l'encouragement des Études grecques on this subject, a detailed summary of which was published in the Revue des Études grecques of the same year. ${ }^{13}$ Thus, it might seem strange that, thirty years after, I visit this

10 A. Palm, Studien zur Hippokratischen Schrift ПEPI $\triangle I A I T H \Sigma$, (Inaug.-Diss.) (Tübingen, 1933).

${ }_{11}$ R. Joly, Hippocrate. Du régime, (Collection des Universités de France) (Paris, 1967).

12 The reference is given supra, no. 1.

13 J. Jouanna, "La théorie de l'intelligence et de l'âme dans le traité hippocratique $D u$ régime: ses rapports avec Empédocle et le Timée de Platon," Revue des Études grecques 79 (1966), pp. XV-XVIII. 
subject again, all the more since the principal findings mentioned in this summary were widely advertised thanks to Joly's editio major of 1984, whom I should thank for the clarity and intellectual honesty with which he signalled each time in his commentary the new interpretations of the theory of the soul in Regimen that I had presented and the new connections with Plato's Timaeus that I had proposed. However, in 1984 Joly still awaited the publication of the paper, which he knew only in its summarised form. Why had I still not published it in its entirety? First, because for a long time I had mislaid the full version of the paper; then because, occupied by other work, I was under the impression that the essential points had already been said in the detailed summary that took up three pages of small font (pp. XVXVIII). However, I became aware that this summary, easily lost amongst the Proceedings of the Association, and paginated, moreover, in roman numerals, is not very appealing. Although it was listed in various bibliographies (Année philologique; G. Maloney's Bibliographie hippocratique; L. Paquet's Bibliographie des Présocratiques), I gladly recognise that one could be forgiven for not consulting it. Its findings, although known to Hippocratic scholars, did not seem to reach the larger public of specialists in Greek philosophy. I was surprised, for example, to see that Luc Brisson's translation of the Timaeus in 1992, ${ }^{14}$ although with an extensive but strictly Platonic bibliography, did not include this summary, even with its explicit title ("The theory of intelligence and the soul in the Hippocratic treatise Regimen: its connections with Empedocles and Plato's Timaeus"); Luc Brisson did not seem to be aware of any of the connections that I had made between Regimen and the Timaeus, despite the fact that they were made available by Joly's international edition.

Thus, I thought that it would be useful to breathe new life into this thirty year old paper by improving it with the nuances that maturity can bring. Hopefully, this invitation to speak at the Centre Léon Robin, extended by my colleague Gilbert Romeyer-Dherbey, whom I most heartily thank, might be the decisive moment which, along with a publication of the full text, will allow a better diffusion of what the Hippocratic Corpus can sometimes bring to our knowledge of pre-Platonic philosophy, and also to our understanding of Plato. ${ }^{15}$

\footnotetext{
14 L. Brisson, Platon. Timée. Critias, (GF Flammarion 618) (Paris, 1992).

${ }^{15}$ Habent sua fata libelli. The present paper was delivered at the Centre Léon Robin of Paris-Sorbonne (Paris IV) on 12 April 1996. It was to be published in the series of the Centre. Unfortunately, due to the negligence of the person responsible for the publication of that
} 
According to the author of Regimen, man, like all living beings, is formed of two basic elements, water and fire, whose mixture varies from one individual to another and determines the constitution of the body as well as the soul. In his account of the soul, towards the end of book 1 , in chapter 35 , the

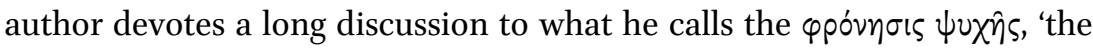
intelligence of the soul', and its opposite, the $\dot{\alpha} \varphi$ poovirn, the 'lack of intelligence'. He systematically presents an explanation as well as a typology of intelligence. For the history of ancient psychology, this is an extremely important document, if only because it is one of the rare pre-Platonic theories of intelligence that has been preserved, other than enigmatic fragments or watered-down doxographies. However, the theory has remained obscure, possibly because it is more exciting to reconstruct what no longer exists than it is to examine what still survives.

It is on this theory that I would like to pause in order to highlight some essential aspects that have not been noticed by commentators; and we will emphasize the particularly close connections which unite this theory to Empedocles and, above all, to Plato's Timaeus.

If we may believe Socrates in Plato's Phaedo (96a-b), the explanation of intelligence was a problem that fascinated the intellectual circles of the

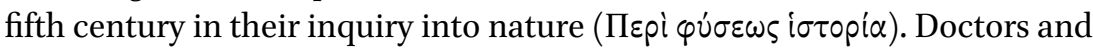
philosophers elaborated brilliant or extravagant ideas on the matter, and the debates flowed. Is intelligence located in the diaphragm, as was believed by some doctors who were more concerned with etymological roots than medical reality, ${ }^{16}$ or in the blood, as Empedocles thought, or in the brain, according to Alcmaeon's discovery? For the author of Regimen, it is found in the $\psi v \times y^{\prime}$, the soul, composed of fire and water; and different degrees of intelligence are to be explained by the different mixtures of fire and

\footnotetext{
year's seminar, the volume that should have been published by Vrin has still not appeared. The present text is that which would have been published in 1996, without any changes. The only other publication concerning chapter 35 of the Regimen that has appeared since then is S. Byl, "Le vocabulaire de l'intelligence dans le chapitre 35 du livre I du traité du Régime," Revue de philologie, de littérature et d'histoire anciennes 76, (2002), 217-224. The author knows and uses the summary of my paper from 1966, quoted supra, n. 13, both for the connections with Empedocles (p. 218) and Plato's Timaeus (p. 222). He studies ch. 35 from the point of view of its vocabulary of intelligence and madness and adds, in this regard, a parallel between ch. 35 of Regimen and Pseudo-Plato's Second Alcibiades, 140c-e.

${ }^{16}$ See the very interesting criticism of this theory in the Hippocratic treatise The Sacred Disease, ch. 17. After this paper, I edited the treatise The Sacred Disease in the CUF (Hippocrate, t. II, third part, [Paris, 2003]). I add references to my edition in the notes. See Jouanna 30,4ff. = Grensemann 86,14 ff. $(=6.392,5 \mathrm{ff}$. L. $)$.
} 
water that constitute the soul. ${ }^{17}$ On this basis, the author constructs a veritable pyramid of different kinds of intelligence, comprising seven categories. At the top, there is the intelligence elite, the $\varphi$ povi $\mu \omega \dot{\omega} \tau \tau \tau$ ( (first category). The water and fire that constitute their soul are in a state of ideal balance. However, most of the time the two constituting elements are in a state of imbalance. Depending on whether water or fire dominates the mixture, we descend along one or the other side of the pyramid. First, we have those cases where the imbalance is due to a predominance of water. If the predominance of water is hardly noticeable (second category), people are still quite intelligent, but they have a slower mind. However, this slowness of mind is compensated by tenacity in work. These are dull but solid minds. If the predominance of water is more marked (third category), the slowness of the mind turns into foolishness. If the predominance of water over fire is extreme (fourth category), insanity occurs ( $\mu \alpha v_{i}$ ); ; yet this is not just any kind of insanity, but the depressive anger of stupid and anxious people who are in a state of total prostration, as though they have been struck by thunder

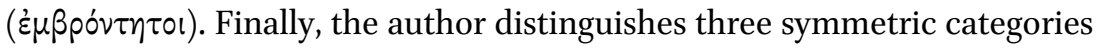
corresponding to the predominance of fire over water. If the predominance of fire over water is weak (fifth category), people are intelligent, and have a lively but not too fickle mind. If the predominance of fire over water is more marked (sixth category), people have a very lively but very fickle mind. These are lively but weak minds. If the predominance of fire over water is extreme (seventh category), the liveliness of the soul is excessive; these people are half-mad and may plunge into insanity at any point. However, this time it is a radically different kind of insanity from the previous one; it is excited madness characterized by hallucinations.

This is a brief summary of the author's curious classification of different kinds of intelligence, which happily combines elegance with geometry, and which applies to the domain of psychology one of the great intuitions of Hippocratic medicine, i.e. the idea that pathology, far from being due to divine intervention, is in fact the rupture of a delicate equilibrium, either in the sense of a hypofunctioning or hyperfunctioning. We should add that this classification of different types of intelligence is not a philosophical exercise totally unconnected to medicine and regimen, the principal subject of the

17 On this theory of intelligence, see K. Fredrich, Hippokratische Untersuchungen (see above, n. 2), who partly re-edited chapter 35 (p. 121f.) and commented on it (pp. 89-110 passim.); R. Joly, Recherches (see above, n. 3), pp. 83-89 and the notes ad loc. of his CMG edition; F. Hüffmeier, "Phronesis in den Schriften des Corpus Hippocraticum," Hermes 89, (1961), 51-84 (III. Phronesis in der Schrift De Victu, pp. 68-84). 
work; the author of the Hippocratic treatise is convinced that he can modify faults in intelligence through an appropriate regimen, by reducing the imbalance between water and fire, the primary elements. Indeed, the author declares with regard to the second category (slight predominance of water over fire): "Given a proper regimen, an individual can become more intelligent and shrewder than his nature would like."18 Thus, a correct regimen improves nature. Each time the author discusses one of the six categories of intelligence characterized by the imbalance between fire and water, he also specifies at length the diet to follow, comprising food, drink and exercises. These recommendations on regimen are useful for an understanding of the author's theory, since he gives not only prescriptions or prohibitions, but he also explains their effects on sensation and intelligence.

This is as far as commentators have got. I too would have left it at that if I had not been struck by a difficulty in the interpretation of this chapter which, by a happy coincidence, provides us with a deeper understanding of our author's theory. This difficulty concerns the third category of intelli-

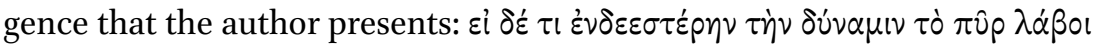

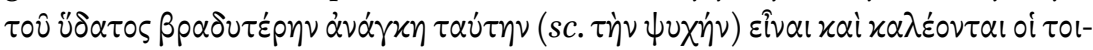

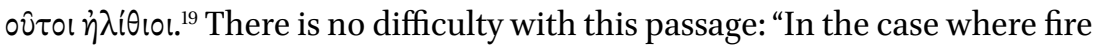
is less powerful than water in an individual, his mind is necessarily slower, and such individuals are called foolish." The author then gives a difficult explanation that does not seem to me to have been well understood by translators:

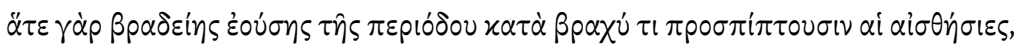

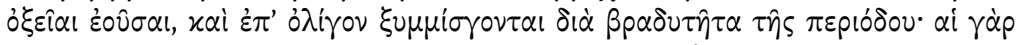

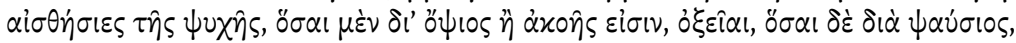

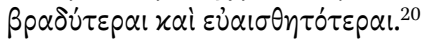

Littré translated the beginning of the sentence as follows: "Indeed, since the circulation is slow, the senses apply only briefly; they are quick, and this slowness makes them become attached only a little."21 This translation is, to say the least, enigmatic. It is difficult to see why the senses that are quick

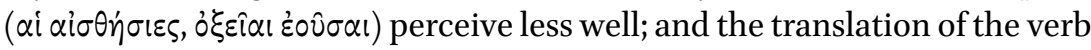

${ }^{18}$ Regimen, ch. 35 Joly CMG 152,12 f. (= 6.514,15 f. L.)

${ }^{19}$ Regimen, ch. 35 Joly CMG $152,28-30$ (=6.516,7-9f. L.)

${ }^{20}$ Regimen, ch. 35 Joly CMG 152,30-33 (= 6.516,9-14 L.).

${ }^{21}$ E. Littré, CEuvres complètes d'Hippocrate, vol. VI (Paris, 1849), p. 517, 11-13: "En effet, la circulation étant lente, les sens ne s'appliquent que brièvement; ils sont rapides, et cette lenteur fait qu' ils ne s'attachent qu'un peu." 


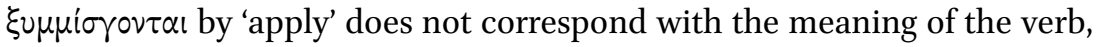
which means 'are mixed'. Jones' translation seems in the first instance more precise: "For as the circuit is slow, the senses, being quick, meet their objects spasmodically, and their combination is very partial owing to the slowness

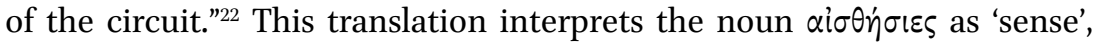
like Littré but, unlike Littré, gives the verb $\xi u \mu \mu i \sigma \gamma o v \tau \alpha$ l the exact meaning of 'to be mixed'. This translation would make sense if 'their' (in 'their combination'), which corresponds to $\xi u \mu \mu i \sigma \gamma o v \tau \alpha$, referred to the objects perceived by the senses. However, since the subject of $\xi_{\nu \mu \mu i \sigma \gamma o v \tau \alpha l}$ is nothing other than $\alpha i \alpha i \sigma \theta \eta$ ' only mean the senses, and I do not see what this curious expression, 'combination of senses', can mean. We will leave the translations here and return to the text.

Before proposing a solution, we must begin with a detailed analysis of the two fundamental notions of this phrase: $\pi \varepsilon p i o \delta \circ \varsigma$ and $\alpha i \sigma \theta \dot{\gamma} \sigma \varepsilon \varsigma$.

The meaning of the word $\pi \varepsilon p i o \delta \circ s$ does not really present any difficulty.

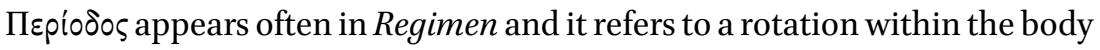
comparable to an astral rotation ${ }^{23}$ However, its use is exceptional within the Hippocratic Corpus. What does this circular rotation refer to? Robert Joly asked this question in his monograph on Regimen, but did not find an

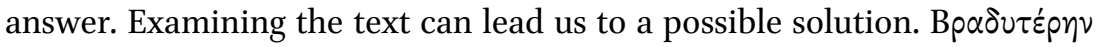

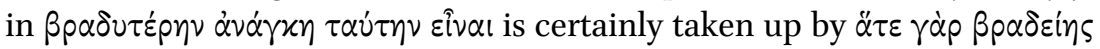

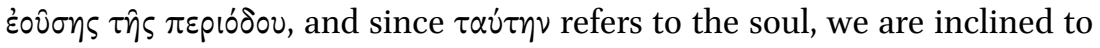
think that it refers to a rotation of the soul. This is confirmed by the context. Something that has not been highlighted by the commentators is that the author of Regimen has a very dynamic and concrete conception of the soul.

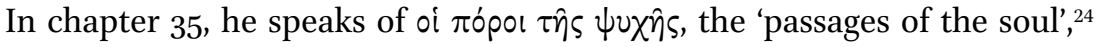

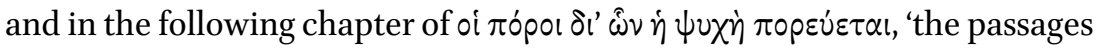

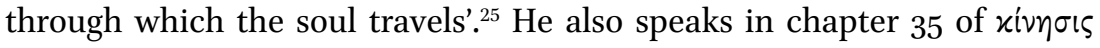

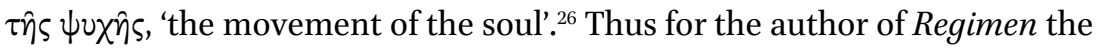

${ }^{22}$ W.H.S. Jones, Hippocrates, vol. IV, (The Loeb Classical Library 150) (Cambridge (Mass.)/ London, 1931), p. 285 .

23 The term is used twice to mean an astral circuit and 15 times in Regimen to mean a circuit within the body; this second meaning is not attested elsewhere in the Hippocratic Corpus. See J.H. Kühn / U. Fleischer, Index Hippocraticus, fasc. 3, (Gottingae, 1988), p. 649, s.v. $\pi \varepsilon p i o \delta$ s.

${ }^{24}$ Regimen, ch. 35 Joly CMG 152,22 (= 6.514,26 L.).

${ }^{25}$ Regimen, ch. 36 Joly CMG $156,25\left(=6.5^{22,24}-5^{24,1} \mathrm{~L}\right.$. $)$.

${ }^{26}$ Regimen, ch. 35 Joly CMG 152,18 (= 6.514,22 L.). 
soul is a fluid composed of fire and water, ${ }^{27}$ which travels through the body

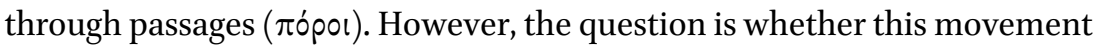
of the soul is circular. I think that we find proof in chapter 25 , which expressly discusses the soul, not intelligence. We find here two symmetrical expressions that are closely similar to that of our passage:

The soul of man, as I said, is composed of fire and water ... it makes its way into every animal that breathes and naturally also in every man, young and old. But it does not develop the same way in everyone; in young bodies, since the

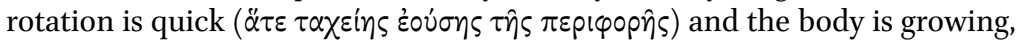
it burns, becomes light and is consumed by the growth of the body; in older

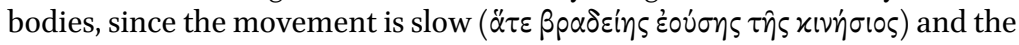
body is cold, it is consumed by the deterioration of the man. ${ }^{28}$

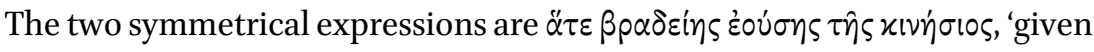
that the movement is slow', - and given the context, this must refer to the

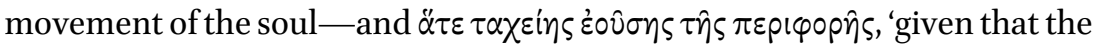
rotation is quick'. The author establishes in chapter 25 a perfect synonymy

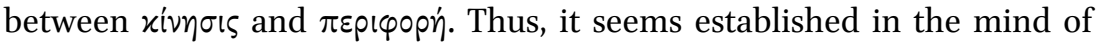
the author of Regimen that the movement of the soul is circular and that $\pi \varepsilon$ piodos in chapter 35 also refers to the rotation of the soul. From now on, we can replace an abstract and static conception of the soul by a dynamic and concrete representation of the soul. The soul rotates within the body.

It even seems possible to be precise about the position of this rotation within the body thanks to chapters 9 and 10, where the author imagines the formation of the structure of the body of man in imitation of the whole ( $\dot{\alpha} \pi \circ \mu i \mu \eta \sigma \nu v \tau 0 \hat{v}$ ö $\lambda \circ v) .{ }^{29}$ We can see how, during the formation of the foetus, after an external crust is formed, the imprisoned fire within the innermost part, nourished by the humidity, begins by digging a hole for the belly, which is the reservoir of humidity, then it digs the channels of respiration and nutrition which open into the exterior, whilst the imprisoned fire in the rest of the body digs three circuits around the belly. These three concentric circuits, which have connections between them, are in the image of the three circuits of the universe; the circuit closest to the belly is analogous to the circuit of the moon; the outermost circuit is analogous to the circuit of the stars, whilst the middle circuit is analogous to the circuit of the sun. ${ }^{30}$

\footnotetext{
${ }^{27}$ Regimen, ch. 25 Joly CMG 142,6f. (= 6.496,20 f. L.).

${ }^{28}$ Regimen, ch. 25 Joly CMG 142,6-12 f. $(=6.496,20-498,5$ f. L. $)$.

${ }^{29}$ Regimen, ch. 10 Joly CMG 134,6 (= 6.484,18 L.).

30 On these three circuits within the body, see F. Hüffmeier, "Phronesis" (see above, n. 17), p. $71 \mathrm{ff}$. The translation of the passage on the three circuits in the CMG edition (p. 134,13-16)
} 
The hottest and strongest fire is located in the middle circuit, and "it is in

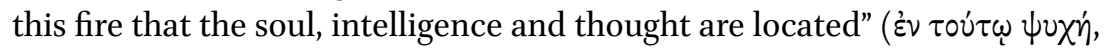

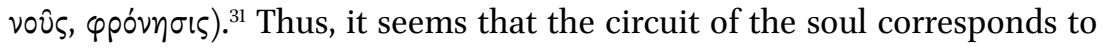
the middle circuit.

The speed of the soul's rotations varies depending on the mixture of the constituent elements, which is in accordance with the general principles of our author. Indeed, for him fire has the property of moving everything continually, and water has opposite properties: "Fire can move everything, water nurtures everything." ${ }^{2}$ From this, we can well understand the workings of our cyclotron. Fire is the accelerator of the particles of the soul; water is its brake. Thus, when water and fire are in equilibrium, the speed of the soul's rotation is ideal. When fire overpowers water, the soul spins faster

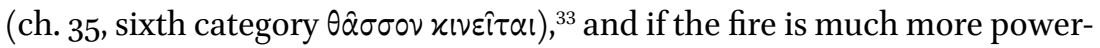
ful than the water (ch. 35, seventh category), it rotates too fast and causes excited madness. On the other hand, if water dominates fire, the soul slows

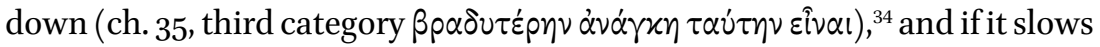
down dangerously, it leads to the madness of stupidity, which the author

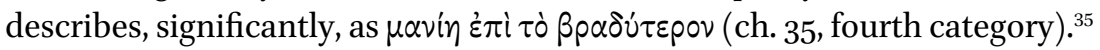
Thus, the author remarkably offers concrete support to the abstract vocabulary of psychology. The liveliness or slowness of the mind corresponds to

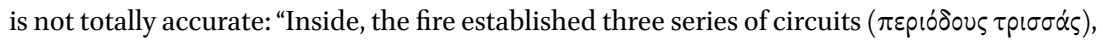
which meet each other inside and outside; one, at the heart of humidity ( $\pi \rho \dot{s} \varsigma \tau \dot{\alpha}$ xoî $\lambda \alpha \tau \hat{\omega} \nu$

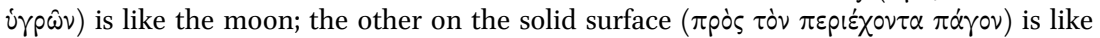
the stars; finally, the middle one, which attaches to both the interior and exterior, is like the sun" ("Là-dedans, le feu a établi trois séries de circuits qui se rejoignent en dedans et au dehors; l' une, au cœur de l'humide, a la capacité de la lune; l' autre, à la surface solide, a la capacité des astres; celle du milieu enfin, qui atteint l'intérieur et l'extérieur, a la capacité du soleil"). But we are dealing with three circuits, not three series of circuits. The innermost circuit, corresponding to the moon, is not at the heart of humidity, but situated "against the hollows of humidity," i.e. the belly. It is the innermost circuit that spins around the belly. The outermost circuit is not on the solid surface, but "against the concretion that surrounds (the body)"; it is the outermost circuit close to the external envelope of the body, like the stars go around the external envelope of the earth. After the presentation of this paper, I wrote a study where I compared the three circuits of ch. 9 and 10 with those of ch. 89: "L'interprétation des rêves et la théorie micro-macrocosmique dans le traité hippocratique du Régime: sémiotique et mimésis," in K.D. Fischer, D. Nickel and P. Potter (eds.), Text and Tradition. Studies in Ancient Medicine and its Transmission, presented to Jutta Kollesch, (Studies in Ancient Medicine 18) (Leiden, 1998), pp. 161-174.

31 Regimen, ch. 10 Joly CMG 134,18 (= 6.486,9 L.).

${ }^{32}$ Regimen, ch. 3 Joly CMG 126,9f. (= 6.472,17 f. L.).

${ }^{33}$ Regimen, ch. 35 Joly CMG 154,22 f. (= 6.520,2 L.).

${ }^{34}$ Regimen, ch. 35 Joly CMG 152,29 (= 6.516,8f. L.).

35 Regimen, ch. 35 Joly CMG 154,9 (= 6.518,4 L.). 
the speed or slowness of the soul, and to the mixture of fire and water that rotates around a circuit enclosed within the body.

Returning now to our text relating to the third category, we find that certain points become clear, but the general sense of the passage is still not clear. There is a further hurdle to overcome, the $\alpha i \sigma \theta \dot{\eta} \sigma ı \varepsilon$. A good strategy might be to translate the passage, whilst leaving the term in the Greek:

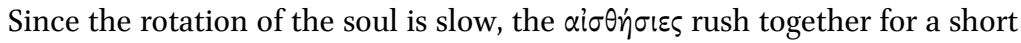
instant each time, since they are quick, and mix together in only a small

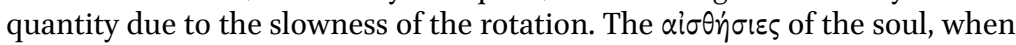
they pass through the channel of sight or hearing, are quick, whilst when they

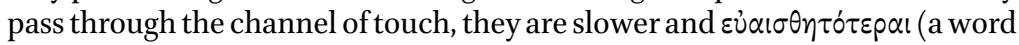

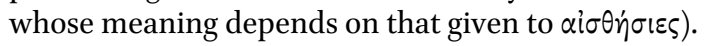

In the singular, $\alpha i \sigma \theta \eta \sigma \varsigma s$ means the faculty of perception in general or sensation. There is no difference for our author between sensation and perception. In the plural, which is what concerns us here, ai $\sigma \theta \dot{\eta} \sigma ı \varepsilon \varsigma$ normally means either sensations or sensory organs. We can immediately disregard a translation of $\alpha i \sigma \theta \dot{\eta} \sigma \varepsilon \varsigma$ with 'sensory organs', since the author tells us that the $\alpha i \sigma \theta \dot{\eta} \sigma \iota \varepsilon \varsigma$ pass through the channel of sight, hearing, touching, i.e. the sense channel. The solution that remains is to translate it as 'sensations'. Unfortunately this hypothesis leads us to an array of difficulties and absurdities, if, at least, we understand 'sensations' in the modern sense. Where do the sensations of the soul hurry to? Towards the object, as translators think. But now, with what do they mix? Above all, how can the sensations of the soul be quick when the soul's rotation is slow? If they were quick, they would hurry to their objects and the soul would be more intelligent, but the author wishes to show us the opposite. Now we arrive at an impasse.

To escape from this impasse, the context will again be of great use to us. Indeed, twice in chapter 35 , the author uses two analogous expressions

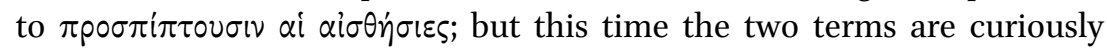
reversed. It no longer concerns $\alpha i \sigma \theta \dot{\eta} \sigma \varepsilon \varsigma$ that rush towards something, but

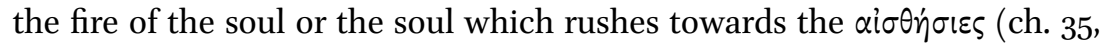

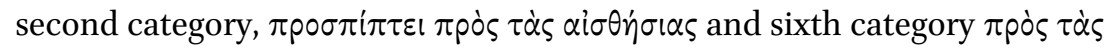
$\alpha i \sigma \theta \dot{\eta} \sigma i \alpha \varsigma$... $\pi \rho \circ \sigma \pi i \pi \tau \varepsilon(v) .{ }^{36}$ There is no contradiction, as we might believe at first, between these two expressions. In fact they express two opposite movements, one of the soul towards the $\alpha i \sigma \theta \dot{\eta} \sigma ı \varepsilon \varsigma$, and the other of the $\alpha i \sigma \theta \dot{\eta} \sigma \varepsilon \varsigma$ towards the soul. We know that for the ancients, in particular

\footnotetext{
${ }^{36}$ Regimen, ch. 35 Joly CMG 152,11 (= 6.514,13 f. L.) and Regimen, ch. 35 Joly CMG 154, 23 (= $6.5^{20,2}$ f. L.).
} 
for Empedocles, intellection is only possible if the objects emit a flux of sensory particles which penetrate the exterior towards the seat of thought. As such, what can $\alpha i \sigma \theta \dot{\sigma} \sigma \varepsilon \varsigma$ mean, if not sensory particles which, coming from the exterior, pass through the sensory channel and penetrate all the way to the soul? Of course, I am well aware that I am attributing to the word a very particular sense here-but we will see that this is not uniquebecause, usually in technical treatises, these particles are designated by

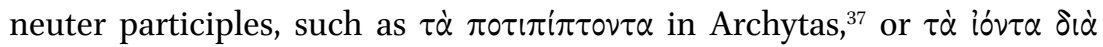
$\tau \hat{\omega} v \alpha i \sigma \theta \dot{\eta} \sigma \varepsilon \omega \nu$ in Plato's Theaetetus. ${ }^{38}$ The author of Regimen also uses the neuter plural in chapter 35 to refer to these elements issued from objects that rush towards the exterior, ${ }^{39}$ and he thus establishes synonymy between the neuter plural $\tau \dot{\alpha} \pi \rho \circ \sigma \pi i \pi \tau 0 \nu \tau \alpha$ and the expression $\pi \rho \circ \sigma \pi i \pi \tau 0 v \sigma i \nu i$ $\alpha i \sigma \theta \dot{\eta} \sigma \varepsilon \varsigma$. In light of this equivalence, both our text and the author's theory of understanding become clear. Understanding comes about when sensory particles ( $\alpha i \sigma \theta \dot{\eta} \sigma \varepsilon \varsigma)$, coming from the object, rush $(\pi \rho \circ \sigma \pi i \pi \tau 0 v \sigma i v)$ towards

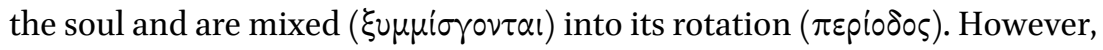
the soul, for its part, is not passive. It is not like the piece of wax of the Theaetetus where the sensory particles leave an imprint. The particles of the soul, animated by their circular movement, rush towards the sensory particles, which are present in the gates of the soul, to catch them. The slower the circuit is, the slower the movement of the soul towards the sensory particles will be; the quicker the rotation is, the more rapid the movement of the soul towards the sensory particles will be. Thus, the more rapid the revolution is, the more sensory particles the soul will digest and the more intelligent it will be. Yet the soul should not turn too fast, because then it would not be able to digest the particles, which would lead to hallucinatory madness.

However, an obscurity remains. The author tells us that the speed of the

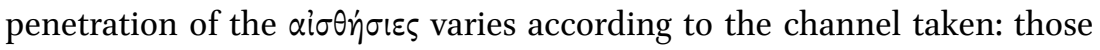
that pass through the channel of sight or hearing are quick, whilst those that pass through the channel of touch are slower ${ }^{40}$ Logically, we would expect those sensory particles that arrive rapidly to penetrate the soul rapidly and

${ }^{37}$ DK 47 B 1 (I, 433,13) regarding sounds that rush towards hearing and are perceived: $\tau \dot{\alpha}$ $\mu \dot{v} \nu$ oง̂v $\pi 0 \tau i \pi i \pi \tau 0 \nu \tau \alpha \pi \circ \tau i \tau \dot{\alpha} \nu \alpha i ̈ \sigma \theta \alpha \sigma i v$.

38 Plato, Theaetetus 194C: "That which penetrates through the sensory channel ( $\tau \dot{\alpha}$ ióv $\tau \alpha$ $\delta i \dot{\alpha} \tau \hat{\omega} \nu \alpha i \sigma \theta \dot{\eta} \sigma \varepsilon \omega \nu)$ is imprinted onto the 'wax' of the soul."

39 Regimen, ch. 35 Joly CMG 154,15 (= 6.518,12 f. L.) concerning the soul which quickly perceives $\tau \hat{\omega} \nu \pi \rho \circ \sigma \pi i \pi \tau \dot{v} \tau \tau \omega \nu$.

${ }^{40}$ Regimen, ch. 35 Joly CMG 152,32 f. (= 6.516,12-14 L.). 
to be mixed in large quantities. However, the opposite happens. Quick

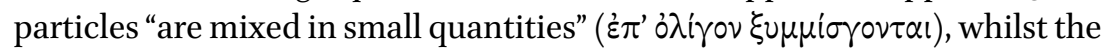

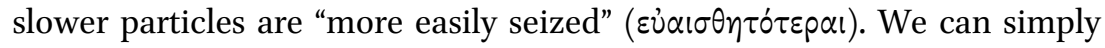
suppose that the particles that arrive rapidly leave again equally rapidly, and only remain for a short instance each time $(\varkappa \alpha \tau \dot{\alpha} \beta p \alpha \chi \dot{\nu} \tau \iota)^{41}$ in the gates of the soul. Conversely, the slower particles leave more slowly, and remain longer in the gates of the soul and can in this way be more easily caught, even if the rotation of the soul is slow. This is why mentally-impaired people, according to our author, still perceive tactile feelings, but not visual or auditory feelings. ${ }^{42}$ Moreover, to understand it, we must think of very concrete experiences, as the ancients did. The sight of a flash of lightning gives the impression of a quick invasion of luminous particles that leave immediately, whilst the feeling of a burn leaves the impression of a slow invasion of hot particles which leave equally slowly and which remain for a long time in the gates of the soul.

Now the difficulties seem to me to be ironed out and the text clearer. Here is my proposed translation:

Since the rotation (of the soul) is slow, the sensory particles have only a short instant each time to rush into it when they are quick, and consequently they can only be mixed together in a small quantity due to the slowness of the rotation. The sensory particles seized by the soul, when they penetrate through the channel of sight or sound, are quick, whilst when they penetrate through the channel of touch, they are slower and more easily seized.

This interpretation was adopted by Joly in his edition of Regimen published in the CUF in 1967 ; it was also adopted without questioning by $\mathrm{H}$. Ioannidi in his paper on "La sensation-perception dans le Corpus Hippocratique," given at the VIIe Colloque International Hippocratique de Madrid (Madrid, 1992), p. 71 f. Joly adopted it in his $1984 \mathrm{CMG}$ edition as well, but he modified it in one respect. Here is what he says in his commentary (p. 259f.):

In my first edition, I adopted the translation and the brilliant interpretation proposed by J. Jouanna ('La théorie de l'intelligence', p. XVIf.). I have also used it here, but in slightly amended form. I no longer accept the translation

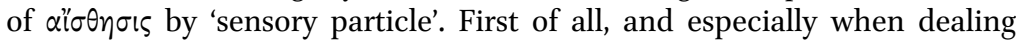
with such difficult texts, I think that the translation should better reflect the possible ambiguity in the Greek. Then, the reason given by J. Jouanna seems

${ }^{41}$ The temporal sense of the expression $x \alpha \tau \dot{\alpha} \beta p \alpha \chi \dot{\nu} \tau \iota$ is perfectly comprehensible. F. Hüffmeier, "Phronesis" (see above, n. 17), p. 81, n. 1 believes that we must understand this expression in a spatial ('räumlich') sense.

${ }^{42}$ Regimen, ch. 35 Joly CMG 152,33-35 (= 6.516,14-17 L.). 
contestable: "The comparison between the two expressions where the terms

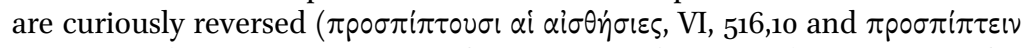

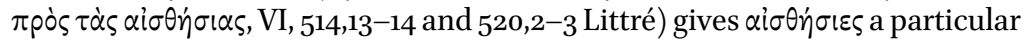
(but not unique) meaning: it concerns sensory particles, emitted by objects, that rush towards the soul and towards which the soul rushes, according to a contrasting yet complementary double movement (p. XVI)." Yet when sensation is the combination of an exterior stimulus with an impression left on the soul, we can therefore say just as naturally that sensation goes towards the soul as the opposite without introducing the notion of sensory particles. There is no discussion anywhere in Regimen of particles emitted by objects, which comes very close to the Democritean view.

In response to Joly's remarks I would like to make the following observations. I gladly concede that the translation 'sensory particles' is explicit and leaves no ambiguity, but I do not believe that the word 'sensations' corresponds to what the author refers to here as $\alpha i \sigma \theta \dot{\eta} \sigma \varepsilon \varsigma ;$ we should at least put sensations in inverted commas in the translation in order to show that the word has a special sense and explain its meaning in a note. If it is true that sensation, in modern usage, is, as Joly says, a conjunction of an exterior stimulus with an impression felt by the soul, it is not this sensation that

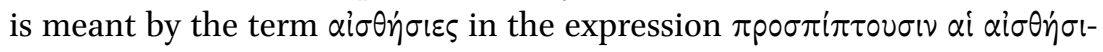
$\varepsilon \varsigma$; these $\alpha i \sigma \theta \dot{\eta} \sigma \varepsilon \varsigma$ correspond to what Joly calls the external stimulus, since the $\alpha i \sigma \dot{\eta} \sigma \varepsilon \varsigma$ rush from the exterior with a speed that varies according to the sensory channel in which they travel, and thus they already exist prior to this conjunction and are not necessarily felt or perceived by the soul. It is easier to gauge the particular sense of $\alpha i \sigma \forall \dot{\eta} \sigma \varepsilon \varsigma$ here by comparing the

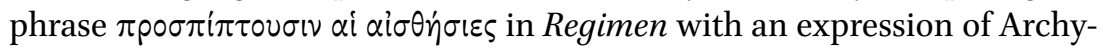
tas (DK 47 B 1), speaking of the sounds that rush towards hearing and are

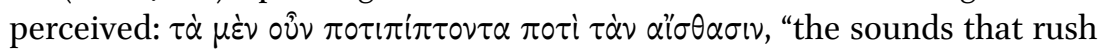
towards $\tau \dot{\alpha} \nu \alpha$ ' $\sigma \theta \alpha \sigma \nu$," a word that may be translated here by 'sensation', or rather by 'sensory organ'. This use of $\alpha{ }^{\prime} \sigma \theta \alpha \sigma \iota$, which presents no difficulty in Archytas, does not correspond to that of $\alpha i \sigma \theta \dot{\eta} \sigma \varepsilon \varsigma$ in Regimen; $\pi \rho \circ \sigma \pi i-$

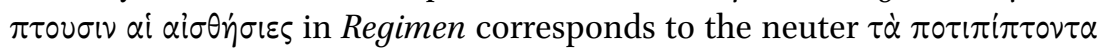
of Archytas. Thus, we cannot translate the term $\alpha$ l $\sigma \theta \eta \sigma \iota s$ in the same way in both passages. The $\alpha i \sigma \theta \dot{\eta} \sigma \varepsilon \varsigma$ of Regimen designate something concrete coming from the object and rushing in from outside in order to be perceived by the soul. We may add that this concrete sense of the plural $\alpha i \sigma \theta \dot{\eta} \sigma \varepsilon \varsigma$ is facilitated by the well-known use, in Greek, of abstract terms in the plural referring to concrete manifestations.

The great difficulty in translating a term like this comes from the fact that in Regimen, the concept of $\alpha{ }^{\prime} \sigma \theta \eta \sigma \iota \varsigma$, which itself was a relatively late creation, still had a large degree of malleability that preceded the distinctions 
that were to be at the root of our modern understanding. A recent doctoral thesis that I supervised with François Skoda, convincingly shows that the verb $\alpha i \sigma \theta \alpha v \sigma \mu \alpha$, from which the noun $\alpha i \sigma \theta \eta \sigma \iota s$ is derived, belongs to a family of words whose initial meaning was that of perceiving by hearing. ${ }^{43}$ The change from auditory perception to perception in general was a remarkable step forward in fifth-century Greek thought, already acquired at the time of Regimen. However, the linguistic distinction between the perceived ( $\alpha \mathrm{i}-$ $\left.\sigma \theta \eta \tau^{\circ} \varsigma\right)$ and the act of perception ( $\left.\alpha{ }^{\prime} \sigma \theta \eta \sigma \iota \zeta\right)$ was not yet known. Moreover, perception could be understood by the same author as a purely receptive process and as an act of the subject (which explains why we find in the same

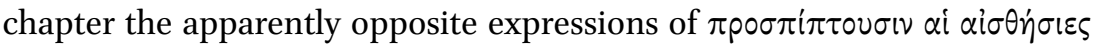
and $\left.\pi \rho \circ \sigma \pi i \pi \tau \varepsilon i \nu \pi \rho \rho^{\prime} \tau \dot{\alpha} \varsigma \alpha i \sigma \theta \dot{\eta} \sigma \alpha \varsigma\right)$, and we must add that there is no difference between sensation/perception and thought in this regard. Our difficulty in understanding and translating an expression such as $\pi \rho \circ \sigma \pi i \pi \tau 0 v \sigma / \nu$

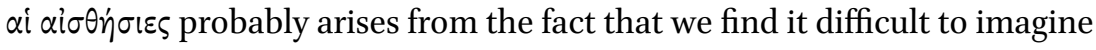
how 'sensation', understood as something completely receptive, can already exist outside a human being before entering the perceiving subject.

Let me add here an example from the Hippocratic treatise The Sacred Disease that illustrates in a similar way our difficulty in understanding the ancients' conception of sensation. The author criticises those who think that the source of thought is the diaphragm or the heart, and he defends the theory that the brain is the source of thought. ${ }^{44}$ This brilliant intuition relies in fact on an idea that has nothing scientific about it, but which represents the process of thought in a very concrete way. The brain is the seat of intelligence because the author is convinced that the brain is the first part of the body to receive the air penetrating through the nostrils, and this part picks out the 'thinking element' contained in the air; thus, the other parts of the body that receive the air, from now on deprived of its thinking faculty, cannot be the seat of thought. Thus, thought is not perceived essentially as an act of the brain. The brain is the receptacle of thought contained in the air, and this receptacle should be a cavity of sufficient volume to store the harvest of the thinking element contained in the air. ${ }^{45}$ Thus, thought

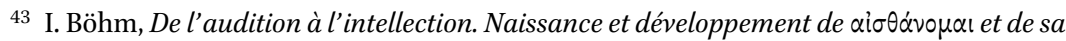
famille de l'époque archaïque à la fin du Ve siècle, (Thèse Paris-Sorbonne [Paris IV]) (Paris, 1996).

${ }^{44}$ For criticism of the diaphragm and the heart as the centre of thought, see The Sacred Disease, ch. 17 Jouanna $30,4 \mathrm{ff} .=$ Grensemann 86,14ff. $(=6.392,5 \mathrm{ff}$. L. $)$. For the brain as centre of thought, see The Sacred Disease ch. 16 Jouanna $29,4 \mathrm{ff}$. = Grensemann 84,23 ff. (= 6.390,10 ff. L.).

45 See The Sacred Disease, ch. 17 Jouanna 30,10 f. = Grensemann 86,18f. (= 6.392,10 L.), 
exists outside the thinking subject. The expression used by the author to indicate that the air "deposits in the brain that which has thought and

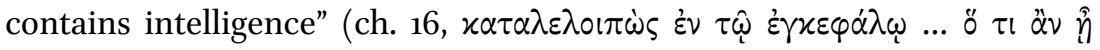

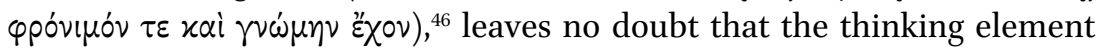
pre-exists in the air before its penetration into man. The author even speaks

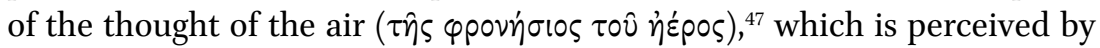

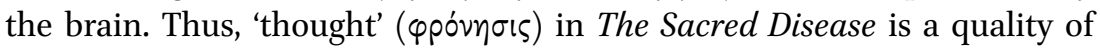
the air, which is deposited in the brain just like, in Regimen, 'perception' ( $\alpha i \sigma \theta \eta \sigma \varsigma)$ is an element that is issued from the object and penetrates the soul. In the concrete imagination of these doctors or intellectuals, action nouns can designate concrete properties outside man, and these action nouns and the corresponding neuters are not always distinguished. This completely passive conception of thought being deposited by the air in the brain, does not prevent the author of The Sacred Disease from conceiving

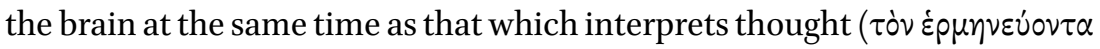
$\tau \dot{\eta} \nu \sigma \dot{v} v \varepsilon \sigma(\nu)^{48}$ and from thereby giving it an active role. Thus for the author of The Sacred Disease, the brain has both a passive and an active role in the process of thinking, just as for the author of Regimen the soul has a passive and an active role in the process of perception. The two texts clarify each other mutually.

Finally, Joly disagrees with the notion of particle, objecting that Regimen nowhere mentions particles emitted by objects, which would be very close to the Democritean way of thinking. On this point, I would like to make two remarks. The first consists in recalling that the author of Regimen employs, in the context of perception, the neuter plural $\tau \dot{\alpha} \pi \rho \circ \sigma \pi i \pi \tau o v \tau \alpha$ to refer to that which comes from the outside and is perceived by the

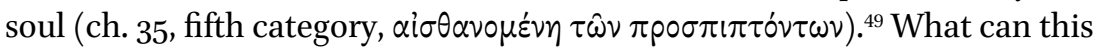
neuter plural mean if not something that emanates from objects, which we might call particles, or corpuscles, or any other word that comes to mind? My second remark is that this conception of perception is not the prerogative of Democritus. Of course, it was the opinion of Democritus, to judge from his theory of eidola or 'images' reported in Plutarch's Table Talk: the eidola emitted from objects and living beings rush in from outside (we

where it is said that the diaphragm cannot be the centre of thought because it does not contain a suitable cavity to receive anything good or bad.

46 The Sacred Disease, ch. 16 Jouanna 29,15 f. = Grensemann 86,7 f. (= 6.390,18-2o L.).

47 The Sacred disease, ch. 17 Jouanna $31,9=$ Grensemann 88,4 (= 6.394,2 f. L.).

48 The Sacred Disease, ch. 16 Jouanna 30,4 = Grensemann 86,12 f. (= ch. 17, 6.392,4 L.).

49 Regimen, ch. 35 Joly CMG 154,15 (= 6.518,12 f. L.). 
find in $735 \mathrm{~b}$ in Plutarch the same participle $\pi \rho \circ \sigma \pi i \pi \tau o v \tau \alpha)$ and penetrate the body through channels $(\delta i \dot{\alpha} \tau \hat{\omega} \nu \pi \dot{o} \rho \omega \nu) .{ }^{50}$ However, this explanation of perception by particles emanating from perceived objects is more generally widespread. There is the well-known opinion of Empedocles, who speaks of 'effluxes' emanating from objects and penetrating the channels ( $\pi$ ópol) of the body (DK 31 B 109 a; cf. A 88; cf. A 86,20 etc.; see the Index of DK, s.v. $\left.\dot{\alpha} \pi \circ \rho \rho \varepsilon \hat{v}, \dot{\alpha} \pi o_{\rho} \rho \rho \circ \alpha\right)$. In Empedocles, the picture is also very concrete: the effluxes are small parts that detach themselves from the object, ${ }^{51}$ even if the metaphor of effluxes (a term derived from the Greek verb 'to flow') contains at the same time discontinuity (drop of liquid) and continuity (flow of the liquid). Without this concrete picture, we cannot make sense of Theophrastus' discussions of effluxes in his De sensibus. With regard to the Empedoclean explanation of the sense of smell by effluxes, here is what Theophrastus says in his critical examination (De sensibus $20=\mathrm{DK}_{31} \mathrm{~A} 86$ ):

Moreover, if there is a deterioration of a body due to the efflux ( $\delta \dot{\alpha} \tau \dot{\eta} \nu \dot{\alpha} \pi \circ$ ppo$\dot{\eta} v)$, the most general sign that Empedocles uses (to explain perception), and if the odours are also produced by a flux ( $\dot{\alpha} \pi \circ p p o \hat{n})$, things that contain the strongest smell would deteriorate most quickly. In fact, almost the opposite happens; for what is most odorous, either plants or something else, is what survives the longest.

This argument supposes that the emanations separated from the objects lead, in Empedocles' theory, to a reduction of the objects, a reduction which is all the larger because the effluxes that detach themselves are more numerous. We should suppose that these effluxes penetrate the human body through the pores which are suited to them. However, this does not mean that we can totally assimilate the effluxes of Empedocles to the eidola of Democritus, since the effluxes of Empedocles evidently do not imply everything that the atoms of Democritus represent, these indivisible particles of different form and size that are dislodged in space. ${ }^{52}$

50 DK 68 a 77 (II 103, 23); cf. also DK 67 A 30 (= Aetius 4.8.10). Leucippus, Democritus and Epicurus say that feeling and intellect are produced when images come from outside; neither

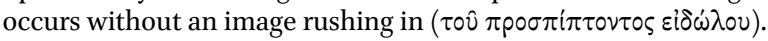

51 See for example, A.A. Long, "Thinking and Sense-Perception in Empedocles: Mysticism or Materialism?," Classical Quarterly 16 (1966), 256-276 (notably p. 26o, "These $\alpha \pi$ óppolal, like everything else, are material and presumably, though we have no evidence on this point, analogous to the $\varepsilon^{\prime \prime} \delta \omega \lambda \alpha$ of Democritus. We may infer that they are qualitatively identical with the body which produces them, for one of the conditions of perception is the reception of $\alpha \pi$ óppoı $\alpha$ by the sense organs").

${ }^{52}$ On this problem, see the very clear and well documented article by M. Laura Gemelli Marciano, "L'Atomismo' e il corpuscolarismo empedocleo: frammenti di interpretazioni nel 
In short, I think that if we separate the problem of the interpretation of the term $\alpha i \sigma \theta \dot{\gamma} \varepsilon \varsigma$ in the passage of chapter 35 of the Regimen from that of its translation (which will always be a transposition, since we will never find in English an identical term that can take into account the full sense of $\alpha i \sigma \theta \eta \sigma$ เs in all the passages), the objections raised by Joly will have to be discarded; at any rate they are not concerned with the essential point.

If this is our author's explanation of intelligence; if it is true that it is based, as we have tried to show, on a rotation within the body; and if this rotation means the rotation of the soul, we can use these new premises to put this

mondo antico," Elenchos 12 (1991), 5-37. The article arrives at a negative conclusion: "The traces of corpuscularism in Empedocles are thus very rare and always presented through the filter of other contemporary or posterior doctrines of atomist or corpuscularist nature" (p. 37). In fact, ancient 'naturalists', in their explanation of perception and intelligence, could subscribe, explicitly or implicitly, to the idea of the flux of perceptible material in the form of particles more or less detached from objects, without agreeing with everything that Democritus' theory of indivisible atoms implies. The desire to attribute to Democritean influence a corpuscular conception of material derived from observations of everyday life (liquid and drops of water; flame and sparks; metal and bodies of metal; wood and sawdust) is simplistic and abstruse. Concerning Empedocles, I find it difficult to agree with M. Laura Gemelli that the theory of $\dot{\alpha} \pi$ oppoxi was interpreted by the most ancient sources (not only Theophrastus in his De sensibus, but also Plato) without reference to corpuscles. Taking the oldest witness, Plato, I do not think that we can establish a distinction between the Empedoclean theory of perception reported by Plato in his Meno $(76 \mathrm{c}-\mathrm{d})$, which was not corpuscular, and the comparable theory reported by Plato in his Timaeus $(67 \mathrm{c}-\mathrm{d})$, which was. It is true that Plato speaks explicitly of $\mu$ ópı $\alpha$ in the Timaeus, whilst the word does not

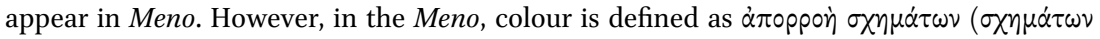
BTWF and not $\chi p \eta \mu \alpha \dot{\tau} \tau \omega \nu$, as M. Laura Gemelli Marciano writes following DK, which adopts

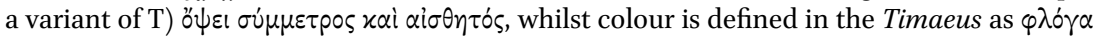

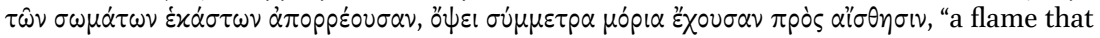
emanates from every sort of body, and has particles adapted to the sense of sight." What else can $\dot{\alpha} \pi \circ p p \circ \eta \dot{~} \sigma \chi \eta \mu \dot{\alpha} \tau \omega \nu$ (which is the reading of the manuscript archetype) mean in the Meno if not the flow of limited elements (cf. the definition of $\sigma \times \hat{\eta} \mu \alpha$ as $\sigma \tau \varepsilon p \varepsilon \circ \hat{v} \pi \varepsilon \varepsilon_{\rho} \alpha \varsigma$ in 76 a), which are detached from perceived objects? In the Timaeus there is no incompatibility between the expression of a continuous flow coming from the objects and the belief that this flow is made up of particles. The flame emitted by objects that defines colour, whilst it

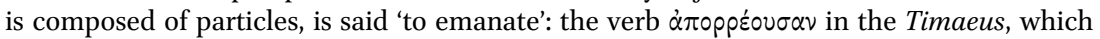
corresponds to the theory of fluxes ( $\dot{\alpha} \pi \circ p$ po $\alpha i)$ enunciated in the Meno, is used with regard to the flow of the flame issued by objects, whilst this flame is said in the same sentence to be composed of particles $(\mu o ́ p l \alpha)$. The model of this representation is the flame which appears in burning wood; it continues burning at its base, it divides into smaller flames and into sparks at the top. Thus, this flame can be quite naturally interpreted as a flux of sparks which seems continuous at its base, where the sparks are numerous and dense, but discontinuous at the top where the sparks become less numerous. This understanding is so natural that even today the word 'spark' is defined in the dictionaries as "a bit of material set alight that rises from a fire" (Le Petit Larousse illustré). 
theory in the context of the biological thought of the end of the fifth and the start of the fourth century BC, i.e. to show the privileged relay role that it was able to play between Empedocles and Plato's Timaeus.

We should be clear that the date of Regimen is not absolutely certain. Following Werner Jaeger in 1938, the treatise was traditionally dated to the fourth century. Robert Joly placed it at the end of the fifth century, but the question remains open. ${ }^{53}$ In any case, it seems highly improbable that Regimen was written after the Timaeus.

That Regimen's classification of different kinds of intelligence is not totally original, but rather inspired by Empedocles, is, since the start of the century, one of the common criticisms of Hippocrates. ${ }^{54}$ However, since a systematic comparison has not been undertaken and since new evidence has emerged, it seems indispensable to return to this comparison. Here is the account given by Theophrastus on the theory of intelligence according to Empedocles, and facing it, the corresponding passages from Regimen.

Theophrastus, De sensu, ch. 10-11

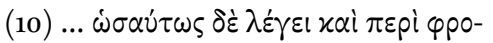

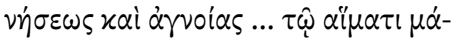

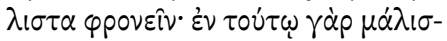

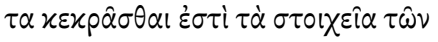
$\mu \varepsilon \rho \omega \hat{\nu}$.

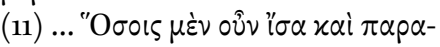

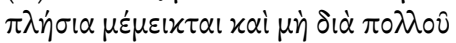
$\mu \eta \delta^{\prime} \alpha \tilde{v} \mu i x \rho \dot{\alpha} \mu \eta \delta^{\prime}$ i $\pi \varepsilon \rho \beta \dot{\alpha} \lambda \lambda \circ \tau \tau \alpha \tau \hat{\omega}$

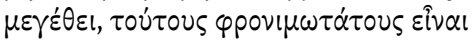

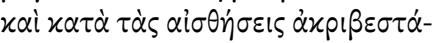

\author{
Regimen, ch. 35 (passim)

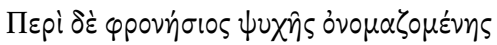

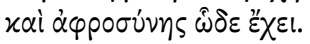

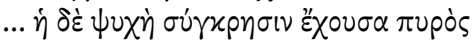

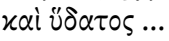

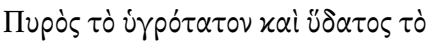

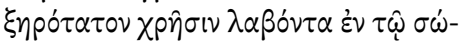

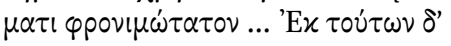 \\ $\dot{\eta} \psi u x \dot{\eta} \sigma u \gamma x p \eta \theta \varepsilon \hat{\imath} \sigma \alpha \varphi \rho \rho \nu i \mu \omega \tau \dot{\alpha} \tau \eta x \alpha i$ \\ $\mu \nu \eta \mu O v i x \omega \tau \dot{\alpha} \tau \eta$.

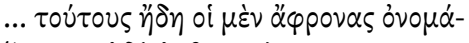

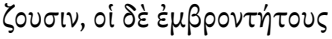

53 See V. Schmidt in Gnomon 45 (1973), 16-18.

${ }^{54}$ R. Joly, Recherches, (see above, n. 3) pp. 88-89, after having connected ch. 35 of Regimen with Theophrastus' account of Empedocles, thinks that this connection was missed by Fredrich. In fact, Fredrich, very attentive to the connections between Empedocles and the Hippocratic Corpus, had made this connection in his Hippokratische Untersuchungen, (see above, n. 2) p. 125, n. 3. On Empedocles, after the oral presentation of this paper, there was an important new discovery with the publication of the Strasburg papyrus: A. Martin and O. Primavesi, L'Empédocle de Strasbourg (P. Strasb. gr. Inv. 1665-1666), Introduction, édition et commentaire, (B.N.U.S.) (Berlin/New York, 1999) (with numerous reviews of the book). However, this has not led to any changes in the text of the present paper. 
Theophrastus, De sensu, ch. 10-11

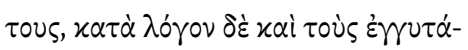

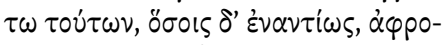

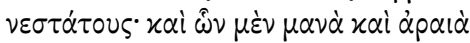

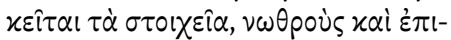

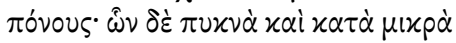

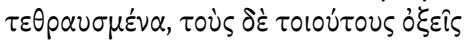

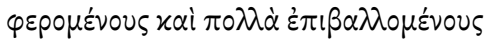

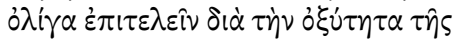

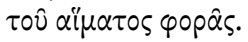

Regimen, ch. 35 (passim)

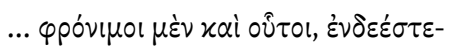

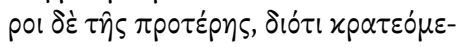

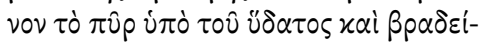

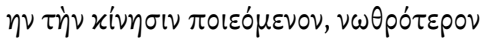
$\pi \rho \circ \sigma \pi i \pi \tau \varepsilon l \pi \rho \dot{\varsigma} \varsigma \dot{\alpha} \varsigma \alpha i \sigma \theta \dot{\eta} \sigma \alpha \varsigma^{\circ} \pi \alpha \rho \alpha-$

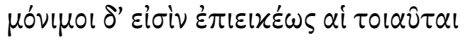

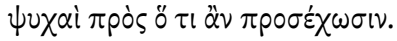

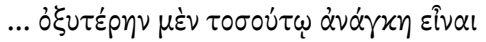

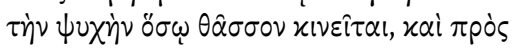
$\tau \dot{\alpha} \varsigma \alpha i \sigma \theta \dot{\eta} \sigma \alpha \varsigma \theta \hat{\alpha} \sigma \sigma o v \pi \rho \circ \sigma \pi i \pi \tau \varepsilon i v$,

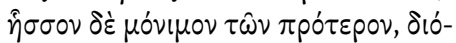

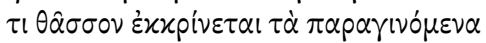

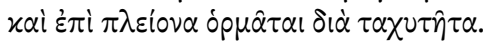

Having discussed how Empedocles envisioned the working of the different senses, Theophrastus comes to the explanation of thought. He begins by explaining that the principle of thought is analogous to sensation; intelligence is produced by things that are similar to each other, whilst its opposite is produced by things that are dissimilar. He then recalls that the seat of thought is the blood, the humour in which the elements are best mixed. ${ }^{55}$ He then expounds a classification of intelligences. I will rapidly go through the most evident comparisons, which have already been picked out by commentators. The philosopher and the doctor tackle exactly the same sub-

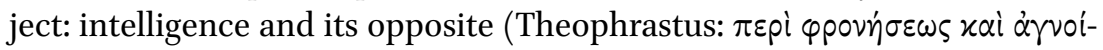

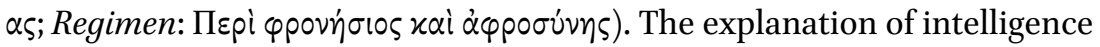
is analogous: the source of thought is a fluid made up of the combination of primary elements which are in a state of mixture (Theophrastus:

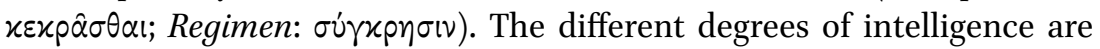
explained by the different types of mixture. It is, in one way or another, an essay in classification of different kinds of intelligence. Empedocles, before the author of Regimen, distinguished the category of the most intelligent

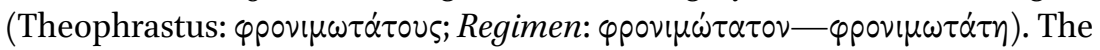
explanation given was the same: the mixture of primary elements is perfect. To this category, Empedocles, before Regimen, contrasted the $\dot{\alpha} \varphi \rho \circ v \varepsilon \dot{\sigma} \sigma \alpha \tau 0$, who owed their foolishness or their madness to the excessive imbalance of the elements. Such comparisons have already been highlighted. They are

\footnotetext{
55 Theophrastus quotes on this occasion two verses of Empedocles (= DK 31 B 107). Compare also DK ${ }_{31} \mathrm{~B}_{105}$ and 110 with the commentary of A.A. Long, "Thinking" (see above, n. 51$)$, p. $267 \mathrm{ff}$.
} 
evident, but Empedocles and the author of Regimen are not the only ones to explain intelligence or its opposite by the balance or imbalance of the constitutional elements.

In the second part of Theophrastus' account the connections become more precise. Between the two extreme categories (the most intelligent and the least intelligent), Empedocles distinguishes two intermediary categories

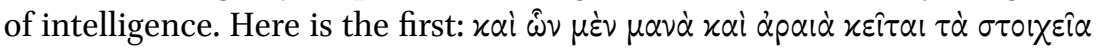

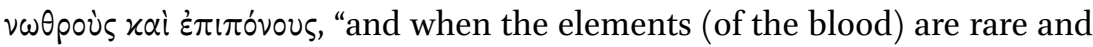

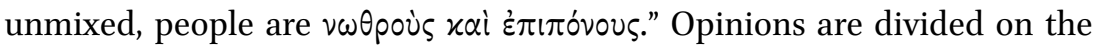
meaning of these two terms. Our dictionaries (Liddell-Scott and Bailly), followed by Robert Joly ${ }^{56}$ and Jean-Paul Dumont, ${ }^{57}$ invite us to translate it by 'slow and quickly tired', giving ह̇ $\pi$ i $\pi$ ovos, uniquely in this passage, a meaning contrary to its normal one. 'E $\pi i \pi$ ovos means 'arduous' and there is no reason here not to give it its normal meaning, as Burnet ${ }^{58}$ and Bollack, ${ }^{59}$ for example, already saw. However, it seems to me that $v \omega \theta$ pov่s and $\dot{\varepsilon} \pi$ iाóvovs refer to different things and mean a lack of intelligence compensated by a quality of temperament. They have a slow spirit ( $v \omega \theta$ poiss) and $(\kappa \alpha i)^{60}$ they are hard working ( $\left.\dot{\varepsilon} \pi \mathrm{i} \mathbf{o}^{\mathrm{v}} \mathrm{ou \varsigma}\right)$. This intermediary category of intelligence is

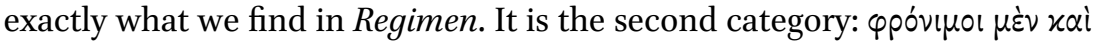

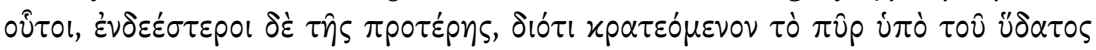

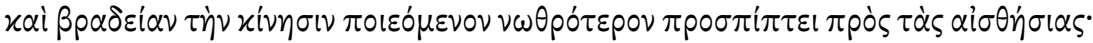

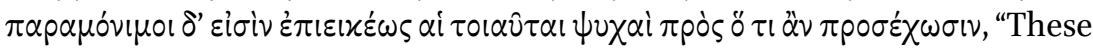
individuals are also intelligent, but less so than the preceding ones because the fire is dominated by the water and therefore has a slow movement and is rushed slower onto the sensory particles; but these souls are rather persistent in whatever they turn their attention to." N $\omega \theta$ pov่ in Theophrastus cor-

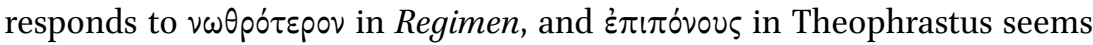
to correspond to $\pi \alpha p \alpha \mu o ́ v i \mu o$ in the Regimen. In both cases, the same lack of intelligence and slowness of spirit is compensated by the same quality of character, tenacity, the desire to work.

${ }^{56}$ R. Joly, Recherches (see above, n. 3), p. 89 ("nonchalants et vite fatigués").

57 J.-P. Dumont, Les Présocratiques, (Bibliothèque de la Pléiade, 345) (Paris, 1988), p. 364 ("lymphatiques et vite fatigués").

${ }_{58} \mathrm{~J}$. Burnet, L'aurore de la philosophie grecque, trad. A. Reymond, (Paris, 1952), p. 283 ("obtus et laborieux").

${ }^{59} \mathrm{~J}$. Bollack, Empédocle I. Introduction à l'ancienne physique, (Paris, 1965), p. 253, n. 5 ("lents et laborieux"). C. Gallavotti, Empedocle. Poema fisico e lustrale, (Scrittori greci e latini) (Milan, 1975), p. 114, translated by "tardi et preoccupati." B. Inwood, The Poem of Empedocles. A Text and Translation with Introduction, (Toronto, 1992), p. 190, understands "sluggish and laboured [in their thinking]."

${ }^{60}$ For this meaning of $x \alpha i$, "and yet," see Denniston GP², p. 292. 
For the second intermediary category of intelligence distinguished by Empedocles, the connections are no less striking. First, here is the text given

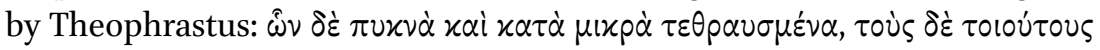

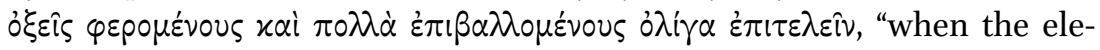
ments are concentrated and divided into small particles, such individuals have a lively mind and, if they throw themselves into many enterprises, they achieve little." Once again, this category finds correspondence in Regimen. It is the sixth category, where fire prevails substantially over water:

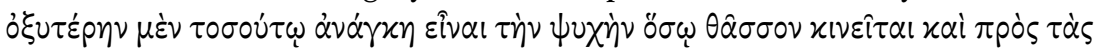

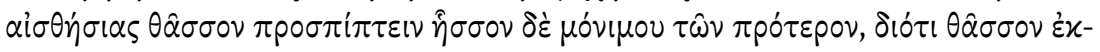

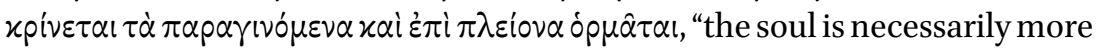
lively since it moves quicker, and necessarily rushes quicker onto the sensory particles, but it is less persistent than the preceding case because it discerns objects presented to it quicker and rushes to more things." This time, both cases concern a quality of intelligence, the liveliness of spirit, which is made lifeless by a lack of character, the lack of tenacity. The connections between the terms used are no less striking. Theophrastus' ȯ $\xi \hat{\imath} \varsigma$

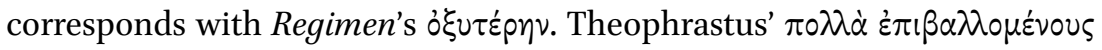

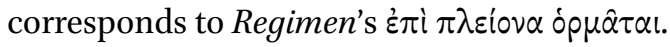

The theory of Regimen is more complex than that of Empedocles, since whilst Empedocles recognises two categories of intermediary intelligence, Regimen has four. We can see the start of a third intermediary category in

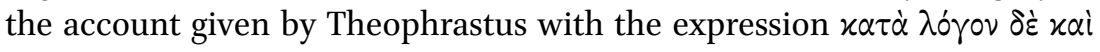

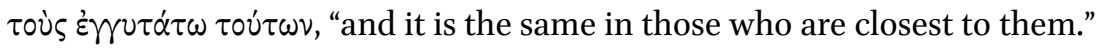
However, in such a context of resemblances, what seems most important for our purposes is the similarity in the explanations given by Empedocles and the author of Regimen in the intermediary category of intelligence where liveliness of spirit is joined to mildness of character. The author of Regimen says $\delta i \dot{\alpha} \tau \alpha \chi \cup \tau \hat{\eta} \tau \alpha$, 'due to the quickness'; we saw above that this can only concern the quickness of the circular movement of the soul. What

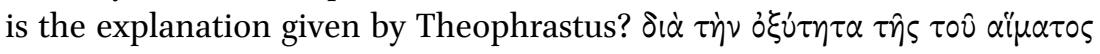

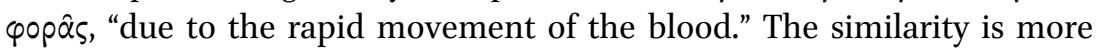
interesting because there is reason to think that the circuit of the soul in Regimen is also the circuit of blood. Indeed, in the section on dreams

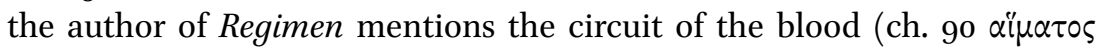
$\pi \varepsilon p$ óo $0 v),{ }^{61}$ which cannot be different from the circuit of the soul.

61 Hippocrates, Regimen, ch. 90, Joly CMG 226, 14 (= 6.654, 20 L.): "Rivers that do not flow as they should are a sign of the circuit of blood, a sign of excess if they flow too abundantly, 
What kind of movement of the blood is at issue in Empedocles? The term

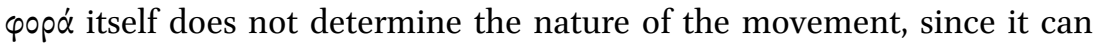
mean any type of movement, not just circular movement, for example that of stars (Plato, Symposium 188b). The fragments of Empedocles do not give very clear information about the movement of blood. The only fragment that alludes to a movement of blood connected to thought is fr. 105, quoted to show that blood is the instrument of comprehension ( $\dot{\omega} \varsigma$ óprávou $\pi$ pòs

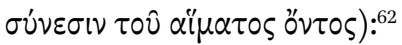

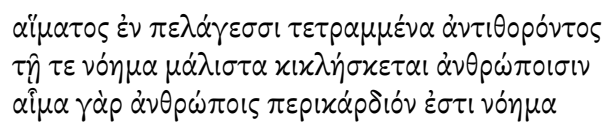

$\tau \varepsilon \tau \rho \alpha \mu \mu \varepsilon \dot{\varepsilon} \alpha \alpha$ codd.: $\tau \varepsilon \theta \rho \alpha \mu \mu \varepsilon \dot{\varepsilon} \eta$ Grotius $\tau \varepsilon \theta \rho \alpha v \sigma \mu \varepsilon \dot{v} \alpha \alpha$ proposuerim e Theophr. De sensi-

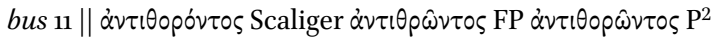

The participle $\alpha v \tau i \theta o p o ́ v \tau o \varsigma$, in the context of a metaphor of the sea, must refer to the movement of blood that dashes forward like a tide. Yet several points remain obscure in this fragment. First, opinions are divided as to whether the feminine participle $\tau \varepsilon \theta p \alpha \mu \mu \varepsilon \dot{v} \eta$ concerns the heart or thought, but it is too often forgotten that this is Grotius' conjecture of a neuter plural participle $\tau \varepsilon \tau p \alpha \mu \mu \varepsilon \dot{v} \alpha^{6 .}{ }^{63}$ If the neuter plural is preserved, "one could make the elements the subject of the participle," as J. Bollack proposes (III, p. 445). Indeed, it is by means of the elements that we think (cf.

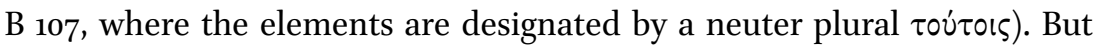
the participle $\tau \varepsilon \tau p \alpha \mu \mu \varepsilon \dot{v} \alpha$, which means "twisted (towards)" does not make

and of a deficit if they flow in too small an amount." On the probable identification of the circuit of blood and the circuit of the soul, see F. Hüffmeier, "Phronesis" (see above, n. 17), p. 76 . We note the identification of blood with the soul in a passage in ch. 35 . In the therapeutic discussion of the sixth category (a quite large dominance of fire over water), the author advises that such people should lose weight in order to become intelligent, and he justifies his treatment as follows: "For the abundance of flesh necessarily leads also to the inflammation of blood, and when this happens to a soul, it becomes mad, with water dominated and fire attracted." This unrest of the soul, as F. Hüffmeier, p. 76 says, is understood best if it is identical to the inflammation of the blood.

${ }^{62}$ Stobaeus 1.49, 53 (extract from Porphyry, On the Styx).

${ }^{63}$ The force of this traditional interpretation of the fragment is such that it has influenced the textual tradition. M.R. Wright, Empedocles: The Extant Fragments (New Haven and London, 1981), obelicizes the text of the manuscripts at the end of verse 1 of the fragment $\tau \varepsilon \tau p \alpha \mu \mu \varepsilon^{\prime} \nu \alpha \dot{\alpha} \nu \tau i \theta \rho \omega \hat{\nu} \tau 0 \varsigma$ (p. 130), but translates and comments as if she adopted Grotius' correction: "(The heart) nourished in seas of blood coursing to and from" (p. 250). J. Bollack is the only one to preserve the neuter participle, rightly remarking (p. 446, n. 2 ) that the first verse seems detached from the one that precedes it. 
sense. ${ }^{64}$ Conversely, if we read $\tau \varepsilon \theta \rho \alpha \nu \sigma \mu \varepsilon \dot{v} \alpha$ (prompted by Theophrastus' account of Empedocles' explanation of thought), ${ }^{65}$ we understand that the elements manifest themselves in the form of fine particles 'broken' in the blood; and these four elements in the form of fine particles carried in the sea of blood are the source of knowledge, following the principle expounded by Theophrastus that, according to Empedocles, we recognise each elementary particle (coming from the outside) with the help of each elementary particle contained within the blood. ${ }^{6}$ Moreover, what is it exactly against which the

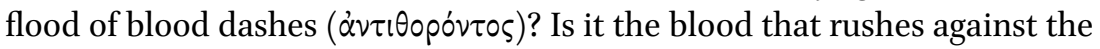
effluxes coming from the exterior, as the soul in Regimen rushes to meet the perceptible particles coming from the outside, given that the processes of sensation and thought are not radically different? The only thing we can be totally sure about is that the blood around the heart (or in the region of the heart) is, for Empedocles, the source of thought.

Taking the strict correspondence between Theophrastus' account of the different categories of intelligence in Empedocles and the exposé of Regimen, we may ask if Empedocles had not already introduced the liveliness of the rotation within the body in order to explain the different types of intelligence. Obviously, this rotation of the blood within the body would not be incompatible with the movements of the blood from the interior to the exterior, which explain respiration in the famous comparison with the clepsydra (DK 31 B 100). ${ }^{67}$ On any account, already in Empedocles, and before Regimen, the theory of intelligence is connected with the liveliness of the movement of a fluid (composed of the mixture of the primary elements) ${ }^{68}$ which is the source of thought, a liveliness that varies depending on the composition of that fluid.

\footnotetext{
${ }^{64}$ The perfect $\tau \varepsilon \tau \rho \alpha \mu \mu \varepsilon \dot{\nu} \alpha$, which marks a state, cannot be translated by "they go (in waves of blood which is splashing back and forth)" (Bollack II, p. 188).

65 The verb is first attested in poetry in Aeschylus (Persians, 416; cf. also 196). Theophrastus in his account would have taken a verb already used by Empedocles. We observe that the verb is used in Aeschylus in the context of vessels broken in a sea battle. Thus, we find an analogy with its use in Empedocles, where the broken parcels of the elements are carried by the sea of blood, like the debris of the vessel broken by the storm.

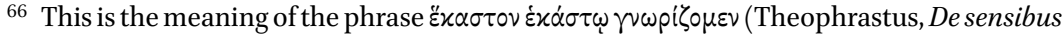
10); cf. B 109.

${ }^{67}$ In the passage on respiration and the comparison with the clepsydra, the movement

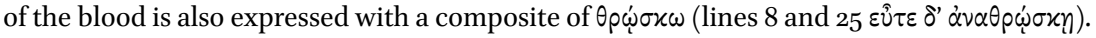
On the comparison with the clepsydra, see D. O'Brien, "The effect of a smile: Empedocles' Theories of seeing and breathing," Journal of Hellenic Studies 89 (1969), 140-179.

${ }^{68}$ With the difference that the primary elements in Empedocles are four in number (fire, water, air, earth), whilst in the Hippocratic doctor they are two (fire, water).
} 
However, compared with Empedocles, the theory of Regimen marks a transposition of historical importance: it concerns not only the circulation of the blood, but also the rotation of the soul. This naturally leads us to think of Plato who, in his Timaeus, explains intelligence and its opposite by the rotations of the soul. We will not exhaustively compare Regimen and the Timaeus, ${ }^{69}$ but simply show that, on the precise problem of the theory of intelligence and the soul, some specific connections present themselves which seem difficult to explain as due to chance. Here are the texts that we will compare:

\section{Regimen:}

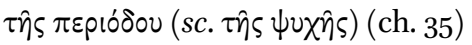

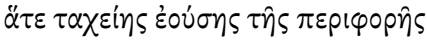

(ch. 25)

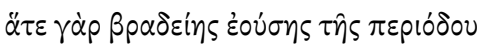
(ch. 35)

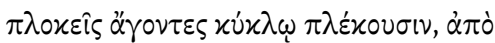
$\tau \hat{\eta} \varsigma \dot{\alpha} \rho x \hat{\eta} \varsigma$ हे $\tau \dot{\eta} \nu \dot{\alpha} p X \dot{\eta} \nu \tau \varepsilon \lambda \varepsilon v \tau \hat{\omega} \sigma l \tau 0 \hat{\tau} \tau$

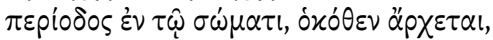

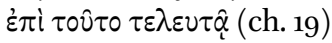

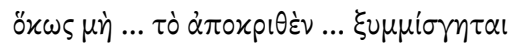
$\tau \hat{~} \psi \cup x \hat{n ~(c h . ~ 35) ~}$

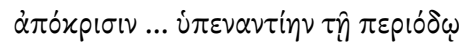
(ch. 93)

\section{Timaeus:}

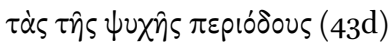

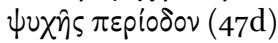

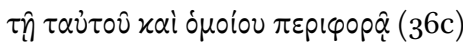

$\tau \hat{~ \tau \alpha u ̉ \tau o v ̂ ~ \varkappa \alpha i ̀ ~ o ́ p o i ́ o u ~ \pi \varepsilon p l o ́ \delta \omega ~(42 c) ~}$

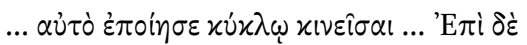

$\tau \dot{\nu} \nu \pi \varepsilon p i ́ \delta \delta$ $\tau \alpha \dot{\tau} \tau \eta$ (34a)

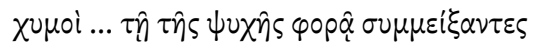

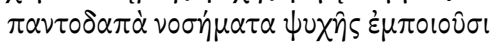
(86e-87a)

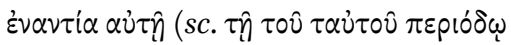

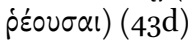

${ }^{69}$ On comparisons between Regimen and the Timaeus, see A. Olerud, L'idée de microcosmos et de macrocosmos dans le Timée de Platon (Uppsala, 1951), pp. 64-66. The author draws our attention to the comparison with circuits in Regimen and the Timaeus. Although my study does not owe its initial idea to Olerud's thesis, which I read later, I will quote fully what Olerud said about the comparison with these circuits: "We note a curious coincidence in the detail of the use of the term $\pi \varepsilon$ piodol, and in the fact that it refers, in the macrocosm,

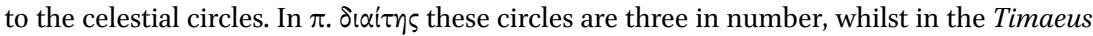
there are only two. However, we observe that one of these two circles is elliptic and includes the solar and lunar circle, as well as all the planetary circles. The main difference is that in the microcosm, these circles correspond to different things. In Plato, they are more or less

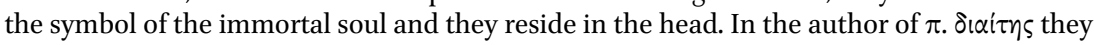
represent certain venous networks. However, here we must not exaggerate the differences. These venous networks are in fact a type of circulation of fire, particularly the intermediary network, which corresponds to the solar circle, and is truly a circle of thought" (p. 64f.). 
Regimen:

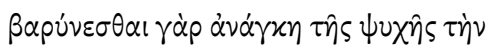

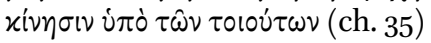

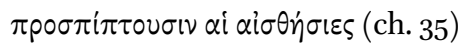

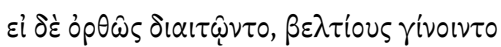

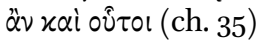

Timaeus:

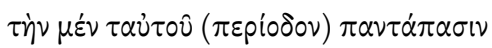
ह่ $\pi \varepsilon ́ \delta \eta \sigma \nu$ (43d)

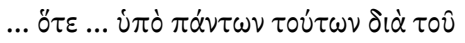

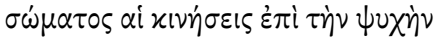

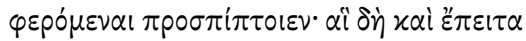

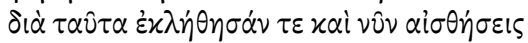

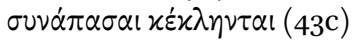

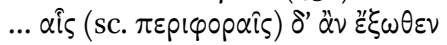

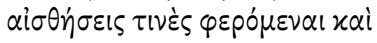
$\pi \rho \circ \sigma \pi \varepsilon \sigma 0 \hat{\sigma \alpha l}(44 \mathrm{a})$

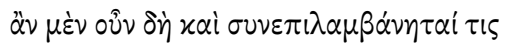

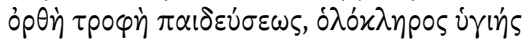
$\tau \varepsilon \pi \alpha \nu \tau \varepsilon \lambda \omega \varsigma \tau \tau \dot{\eta} \nu \mu \varepsilon \gamma(\sigma \tau \eta \nu \dot{\alpha} \pi \circ \varphi v \gamma \hat{\omega} \nu$

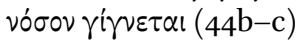

We know that for Plato, in the Timaeus (and only in the Timaeus) the movement of the immortal soul is also circular. The first coincidence is that Plato calls these movements by the same term as the author of the

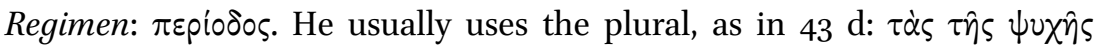
$\pi \varepsilon p$ ódous, which is only natural as he distinguishes two rotations, that of the Same and that of the Other. However, he also uses the singular to mean not only the revolution of the two circles, but also that of the entire soul, as

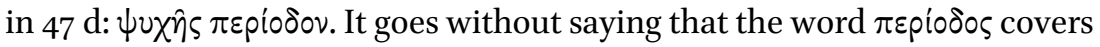
exactly the same notion in both authors. It does not mean just any cycle, but rather a circular rotation, as is shown in both authors by the significant

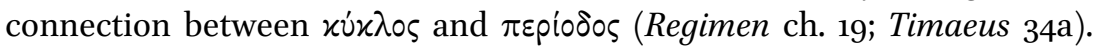
There is another verbal coincidence that merits attention. To designate the rotation of the soul, both employ a synonym of $\pi \varepsilon p i o \delta \circ \varsigma, \pi \varepsilon p ı \varphi \circ \rho \dot{\text {. In }}$ Regimen, the interchangeability between the two terms is clear from the

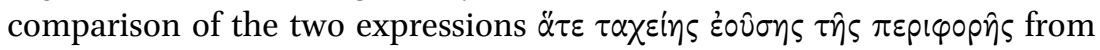

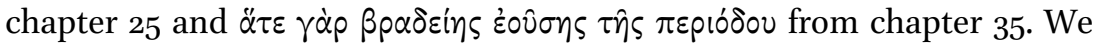
also find this synonymy in the Timaeus, where Plato designates, without

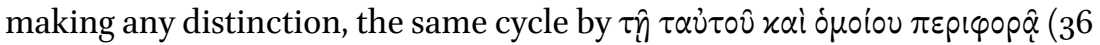

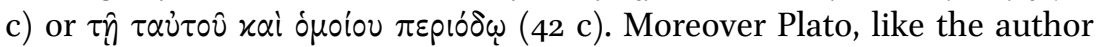
of Regimen, connects the rotations inside the body with astral cycles. Even though the correspondence between bodily and astral rotations is not the same in all detail, since Plato's astronomical system is more complex than 
that of Regimen, it nevertheless remains that both held very similar ideas about the correspondence between the structure of the microcosm and the macrocosm.

Here, then, are some very close parallels. In both the Timaeus and Regi$m e n$, the soul travels in rotations, and these rotations are called by the same name and are connected with astral rotations. However, we should be careful here. These analogies do not permit us to conclude, for the moment at least, a direct influence of Regimen on the Timaeus, since these two theories, even if they are close to each other, could derive independently from a common source ${ }^{70}$ possibly Pythagorean. ${ }^{71}$ I will gladly leave this problem of a common source in parentheses because, even if certain aspects of the theory of the $\pi \varepsilon p i o \delta$ s of the soul in the Timaeus and Regimen can be traced back to a common source, this does not exclude the hypothesis of a direct influence of Regimen on the Timaeus, if only for the very specific medical ideas they have in common. Thus, we will continue the comparison.

Both works clearly connect intelligence with the rotations of the soul. We saw that, for the author of Regimen, intelligence was perfect when the speed of the soul's rotation was perfect. The explanation given by Plato in the Timaeus is comparable. When the rotations of the Same and the Other are at their ideal speed and trajectory, knowledge, whether rational or perceptual, are perfect. By contrast, both in the Timaeus and in Regimen, disturbance of the rotations of the soul causes mental disorder, even leading to insanity. Especially in its account of mental pathology, the Timaeus appears extremely close to the Regimen. I refer in particular to those striking passages where Plato describes mental disorder arising from the entrance of the immortal soul's rotations into the body $(43 \mathrm{~b}-44 \mathrm{~b})$. Once bound to the body, the soul, Plato tells us, has grave troubles. Its rotations are disturbed. The rotation of the Other is dislocated, that of the Same is slowed, if not stopped. The soul, incapable of discerning the Same from the Other, finds itself deprived of intelligence (ávous). To explain these troubles, Plato advances two physiological causes which attract our attention. The first is the abundant tide of nutriment that flows in and out of the body (cf. $43 \mathrm{~b}$

${ }^{70}$ In his discussion of the date of Regimen, V. Schmidt (Gnomon 45 [1973], 18, n. 3) states: "Dieselbe Erwägung (sc. the possibility of a common model) gilt auch für das Verhältnis zu Platons Timaios, in dem Jouanna $R E G$ 79, 1966, XVIII, Einfluss von Vict. zu erkennen glaubt." V. Schmidt does not say what this common model might be.

71 See A. Olerud, L'idée de microcosmos et de macrocosmos, (see above, n. 69) p. $69 \mathrm{f}$. and R. Joly, Recherches, (see above, n. 3) p. $5^{2}$, which is less affirmative, noted the paucity of our information. 


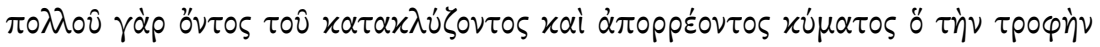
$\pi \alpha p \varepsilon \hat{\chi} \chi \varepsilon \nu)$. This is an unusual idea. How can an abundance of nutriment disturb the rotations of the soul? To be sure, Plato's text is not very clear about this process. However, it is relatively easy to reconstruct his view by comparing it with another passage from the Timaeus (86e-87a), where Plato explains the diseases of the soul by an unhealthy state of the body, by a state of abundance of nutriment leading to ignorance and forgetfulness, a state of plethora which seems to mimic the initial disorder of the incarnate soul, although with less intensity. This is the process: the tide of food leads to a state of plethora. With this plethora, the humours secreted by this food (phlegm and bile) wander around the body and if they cannot evaporate to the exterior, they congregate inside, they mix the vapour issued from them with the movement of the soul and they mix them-

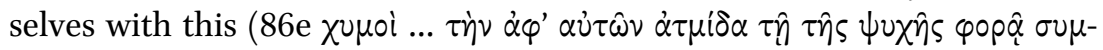
$\mu \varepsilon \dot{\xi} \alpha \nu \tau \varepsilon \varsigma \dot{\alpha} \nu \alpha \kappa \varepsilon p \alpha \sigma \theta \hat{\omega} \sigma l)$. This is how they cause diseases of the soul (ibid.

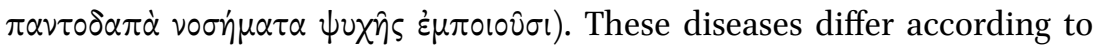
the part of the soul affected; if it is the part of intelligence, the plethora

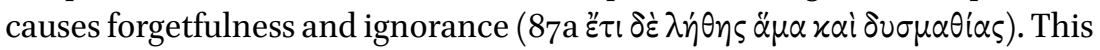
shows that Plato had a concrete conception of the soul, at least when it is embodied. Following a process analogous to that of the incarnation of the soul, the humours coming from the food penetrate the rotations of the soul; instead of being led by the rotation of the Same, they are opposed

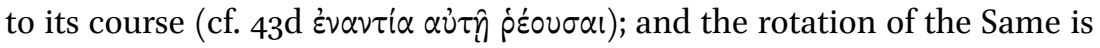
slowed and hindered (cf. 43d $\tau \dot{\eta} \nu \mu \dot{\varepsilon} \nu \tau \alpha \nu ं \tau 0 \hat{v} \pi \alpha \nu \tau \dot{\alpha} \pi \alpha \sigma \nu \nu \dot{\varepsilon} \pi \varepsilon \dot{\delta} \eta \sigma \alpha \nu$ ), whilst

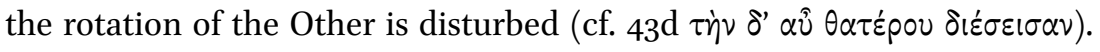
All these perturbations lead to the initial madness of the soul's incarnation (44b). In short, the abundance of nutriment is, for Plato, an essential factor in the perturbations of intellect, not only in the initial incarnation of the soul but also when plethora leads to disturbances in the soul's rotations and troubles of thought such as forgetfulness and ignorance.

This theory is entirely comparable to that found in the Hippocratic treatise Regimen. The author places great importance on considerations of intelligence because he was convinced that an unhealthy regimen could have a negative influence on intelligence. The process involved was analogous. When there is plethora, whether from nutriment or exercise, the humours secreted are mixed with the soul (ch. 35, second category concerning the

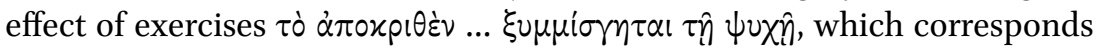

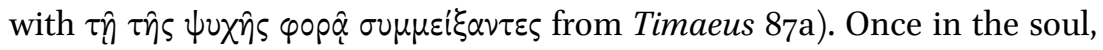

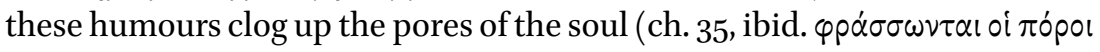


$\tau \hat{\eta} \varsigma \psi \cup \times \hat{\eta} \varsigma$ ) and slow down its movement (ch. 35, second category, following

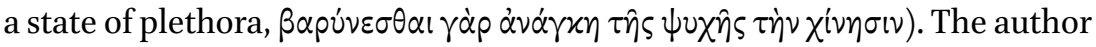
of Regimen equates disturbance of intelligence with the slowing down of the soul. According to Regimen, as in Plato's Timaeus, the secretion is sometimes opposed to the rotation. This process is mentioned by the author of Regimen at the very end of his work in a discussion of the category of dreams that foretell trouble of the body. Here is what he says (ch. 93): "Each time (in a dream) one is hit, bitten or enslaved by something else, this means that

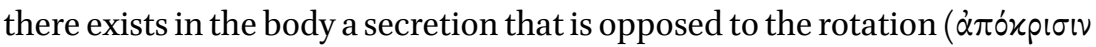
... i $\pi \varepsilon v \alpha v \tau i \eta \eta \nu \tau \hat{\eta} \pi \varepsilon p i o \delta \delta \omega)$." The author of Regimen does not indicate precisely which rotation he has in mind, but this process is in any case comparable to that of the Timaeus, where the rotation of the soul is also hindered by a fluxation coming from the exterior, which is opposed to it ( $\dot{\varepsilon} v \alpha v \tau i \alpha \alpha$ -

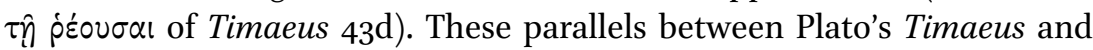
the Hippocratic treatise Regimen are based on a very detailed medical theory that was discussed in depth by the Hippocratic doctor. The coincidence seems to be very convincing here, and very difficult to put down completely to chance.

However, in these pages from the Timaeus, there is another, even more decisive coincidence which concerns not only the impact of regimen on intellect, but the theory of sensation itself. To explain the troubles of the soul arising from its incarnation, Plato introduces a second and more important factor of trouble for the soul, over and above the invasion of nutriment: the invasion of the perceptible, which rushes in mass to the soul $(43 \mathrm{~b}-\mathrm{c})$ :

For while the flood which foamed in and streamed out and which supplied the nutriment was immense, still greater was the great trouble produced by the effects caused by the particles which rushed towards each individual ( $\tau \dot{\alpha}$ $\tau \hat{\omega} \nu \pi \rho \circ \sigma \pi i \pi \tau \dot{v} v \tau \omega \nu \pi \alpha \theta \dot{\eta} \mu \alpha \tau \alpha$ ), each time someone's body collided with an alien fire from the exterior that it met by chance, or with a solid lump of earth or liquid glidings of waters, and if the body was seized by a storm of winds driven by air, and when the motions due to all these causes rushing through the channel of the body, the

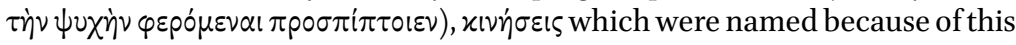
and are still called $\alpha i \sigma \theta \dot{\eta} \sigma \varepsilon ı$ today.

(Transl. W.R.M. Lamb, modified)

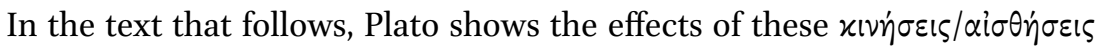
which, jointly with the perpetual flood of nutriment, strongly disturb the

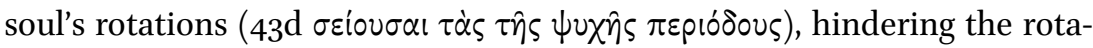
tion of the Same by flowing contrary to it and preventing its domination, whilst they disturb completely the rotation of the Other, all of which lead to errors and insanity. 
A little later in the same passage, Plato returns to the effect produced by the $\alpha i \sigma \theta \dot{\eta} \sigma \varepsilon ı$ s of the soul's rotations. Here is the text that seems to me to be the most important (44a):

The rotations of the soul towards which the $\alpha i \sigma \theta \dot{\eta} \sigma \varepsilon ı$ are carried and collide

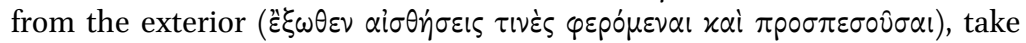
with them the whole vessel of the soul, whilst these rotations, though actually mastered, appear to have the mastery. Thus, because of all these affections, now as in the beginning, the soul becomes at first irrational ( $\alpha$ vous) when it is bound within a mortal body.

(Transl. Lamb, modified)

There seems to be an undeniable connection between the use of $\alpha$ i $\sigma \dot{\eta} \sigma \varepsilon ı$ in this passage of the Timaeus and in ch. 35 of Regimen, because we find

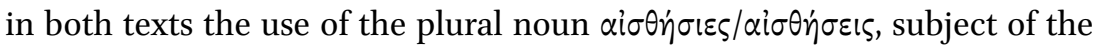
same verb of movement $\pi \rho 0 \sigma \pi i \pi \tau \varepsilon i \nu$ (Regimen ch. 35, third category $\pi \rho \circ \sigma-$

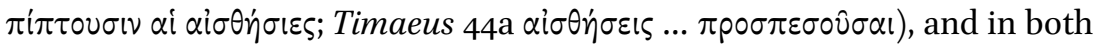
cases it concerns the same movement of transfer of sensory particles coming from the exterior and issued from objects, and of the same movement of penetration of these sensory particles against the rotation of the soul by the corporeal channel of the senses. We could add that the sensory particles coming from the exterior have a comparable effect on the soul. Indeed, we

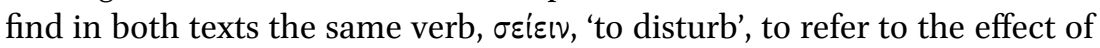
the sensory particles on the soul (Regimen ch. 35, number $3 \ddot{\eta} \nu ~ \gamma \dot{\alpha} \rho \mu \eta \dot{\eta} \sigma \varepsilon i \sigma \theta \hat{\eta}$ $\dot{\eta} \psi u x \dot{\eta}$ نं

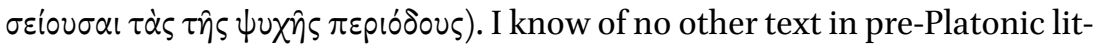
erature that is so close to the Timaeus as that of Regimen, both for its theory of sensation / perception / intelligence tied into the rotations of the soul and for the use of $\alpha i \sigma \theta \dot{\eta} \sigma \varepsilon \mid \varsigma$, referring to the sensory particles which come from objects and which are enlivened by an autonomous movement towards the subject. This dynamic representation of $\alpha i \sigma \theta \dot{\eta} \sigma \varepsilon ı$ finds etymological support in the text of the Timaeus, if we use the phrase where Plato justifies the

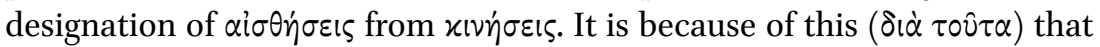
they are called $\alpha i \sigma \theta \dot{\eta} \sigma \varepsilon ı \varsigma$, i.e. because they were moving. Thus, Plato justifies the name $\alpha i \sigma \theta \dot{\eta} \sigma \varepsilon ı$ with an etymological explanation which connects the noun with a term designating movement. Whilst Plato is not more explicit, since for him it is an obvious fact, it is clear that Plato, in an etymological explanation comparable to those which we find in his Cratylus, associates the root $\alpha i \sigma$ - of $\alpha i \sigma \theta \dot{\eta} \sigma \varepsilon ı \zeta$ with that of $\alpha i \sigma \sigma \sigma \omega$, 'to dash forward'. It matters little that this etymology does not correspond to the etymology modern philologists attach to $\alpha i \sigma \theta \dot{\alpha} \nu 0 \mu \alpha$ and the action noun $\alpha i \sigma \theta \eta \sigma \varsigma$, , which derives from the older verb $\alpha$ ' $\omega$, which means 'to hear' (cf. P. Chantraine, Dictionnaire étymologique de la langue grecque: "The connection between $\alpha i \omega \omega$, 'to hear, 
perceive' and $\alpha i \sigma \theta \alpha$ 'vo $\mu \alpha$, 'to feel, perceive' is almost certain"). The essential point is that Plato's representation of $\alpha i \sigma \theta \dot{\eta} \sigma \varepsilon ı \zeta$ cannot correspond uniquely to that which we call sensation, i.e. the conjunction of a stimulus and of a

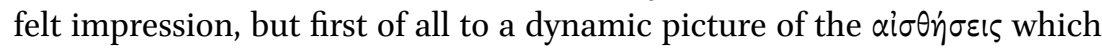
come from the exterior before penetrating to be perceived. Also when Plato

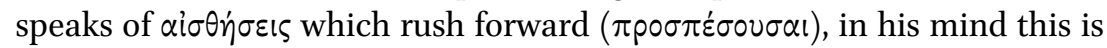
almost a figura etymologica, given that Plato attaches the root of the action noun $\alpha i \sigma \theta \eta \sigma \varsigma \varsigma$ to $\alpha i \omega \sigma \omega$, 'to dash forward'. The $\alpha i \sigma \theta \dot{\eta} \sigma \varepsilon ı \varsigma$ mean here, as in Regimen, above all the 'sensory particles', which will be called in Aristotle's De anima $\alpha i \sigma \theta \eta \tau \dot{\alpha}$. However, these sensory particles, to the extent that they are called by an action noun ending in - $\sigma / \varsigma$ and not by a verbal adjective in

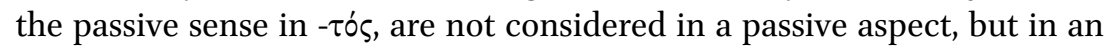
active and dynamic one. It is this dynamic aspect of 'movement' that Plato recovers in his etymology.

We should note that this implicit etymology of Plato, that I have made explicit by the examination of the text, had already been proposed by Proclus in his Commentary on Timaeus (ed. E. Diehl 3.332, 3-16). However, Proclus adds a refinement: he considers that the root al $\sigma$ - comes from dit $\sigma \sigma \omega$, 'to dash forward', but he associates the end of the wordto $\tau^{i} \theta \eta \mu$, 'to place', which applies only approximately, since we would

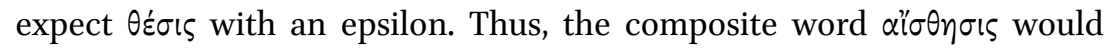
combine two opposites, movement and rest. It is clear that this refinement does not correspond to Plato's text, which associates the word with the idea of movement, but we understand the rationale of this refinement, which allows a conception of $\alpha$ il $\theta \eta \sigma \varsigma s$ that is closer to the usual meaning of 'sensation'. Indeed, Proclus comments on this double aspect, saying: "sensory particles are on the one hand moved from the exterior, and on the other placed in the sensory organs." Thus, we find this remarkable use of the word al $\sigma \theta \eta \sigma \iota \varsigma$, which we encountered in Regimen in relation to the sensory particles coming from the exterior, again very clearly in the passage of the Timaeus just quoted, which echoes Regimen. There, the coincidence appears less due to chance than anywhere else because nowhere in the Theaetetus, nor in the rest of the Timaeus, is this use of $\alpha i \sigma \theta \dot{\eta} \sigma \varepsilon \mathrm{s}$ found. Of course, it is quite possible that chapter 35 of Regimen and this very clear passage of the Timaeus are the only witnesses of a technical sense of the word that had currency in the medical and philosophical writers of the end of the fifth and the start of the fourth century. However, it is not unreasonable, in the light of the cluster of other similarities we have found, to think that Plato borrowed from Regimen here directly. In short, although we cannot totally exclude the explanation of certain convergences by a 
common source, it is not improbable to conclude that Plato knew Regimen and that he had read with particular interest its discussion on the theory of intelligence.

However, despite the resemblances, there is an important transposition in Plato compared to Regimen which marks an important stage in the history of theories of thought: Plato does not situate the rotations of the soul in the region of the belly, but in the brain. Does this allow us to think that Regimen was one of the catalysts that later revealed to Plato an idea that he would hold dear until his death, that of the explanation of intelligence by the rotations of the soul? In any case, the treatise Regimen, in virtue of its explanation of intelligence by reference to the speed of a rotation within the body, seems a neglected link of the chain which, in theories of perception and thought, should link Empedocles to Plato's Timaeus. ${ }^{72}$

72 This evidently does not exclude a direct influence of Empedocles on the Timaeus; on this problem, see J.P. Hershbell, "Empedoclean Influences on the Timaeus," Phoenix 28 (1974), $145^{-166 .}$ 